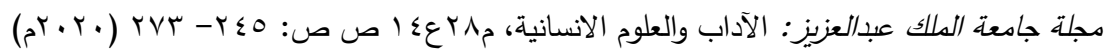

$$
\begin{aligned}
& \text { DOI:10.4197/Art.28-14.7 }
\end{aligned}
$$

دلالات الخطاب السياسي السعودي

دراسة سيميائية لخطابات الأمير سعود الفيصل

\author{
د. دبد اللطيف السلمي \\ أستاذ اللسانيات المشارك \\ (كلية العلوم والآداب بالكامل - جامعة جدة- السعودية)
}

مستخلص. تحاول هذه الدراسة تسليط الضوه على إثكالية العلاقة بين اللغة والسياسة عامة، ثم الصيغة التي يُبنى بها الخطاب السياسي عند الأمير سعود الفيصل سيميائيًا على نحو خاصّ. وكيف استطاع هذا الخطاب بناء نموذج سياسي قادر بمفاهيمه وبآلياته الحجاجية والبلاغية فلكّ شفرات الأزمات الإقليمية والتحولات الدولية وفي ودي

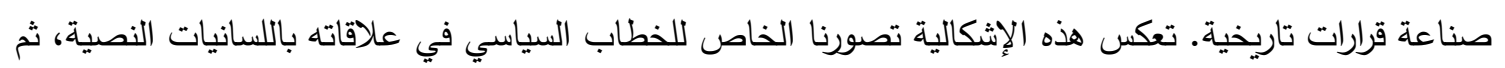

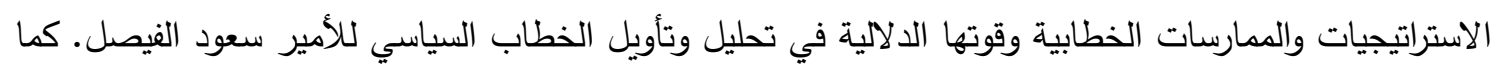
اعتمدت الدراسة إطارًا تحليلًا على نهج فيركلف والدراسات السيميائية التي تولّي أهمية خاصة للمعجم والتركيب واللغة، إلى جانب اهتمامها بتحليل الإثكال في العلاقات والاستراتيجيات داخل السلطة. وتكمن أصالة هذا النهج في مزجه بين المقاربة النصية والمقاربة النقدية للخطاب وتحليله. الكلمات المفاتيح: اللغة - السياسة - الخطاب - السيميائيات - سعود الفيصل - التحليل النقدي للحطاب.

الخطاب السياسي ظلَّ من الأمور الصعبة التحديد، لا سيما أنه يقع في الحدود بين تخصصين هما اللسانيات وعلم السياسة، وكل تخصص يعرّقُ

\section{المقدمة}

على الرغم من الاهتمام المبكر والحديث المتواصل

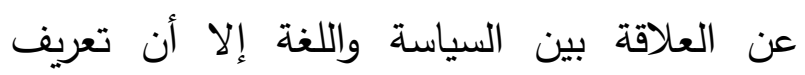


الخطاب السياسي انطلاقًا من جانب معين كما أن الحجاجية والبلاغية فلكّ شفرات الأزمات الإقليمية

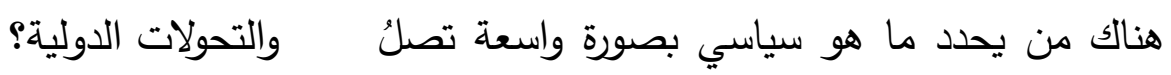

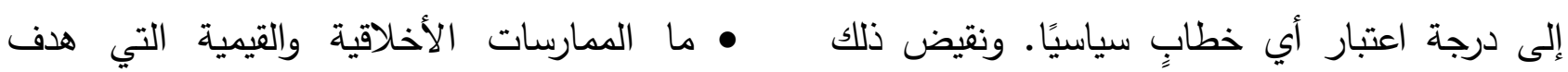
يقع عند تطبيق القيود الثكلية على تعريف الخطاب الأمير سعود الفيصل إلى تحقيقها في خطابات الثاته

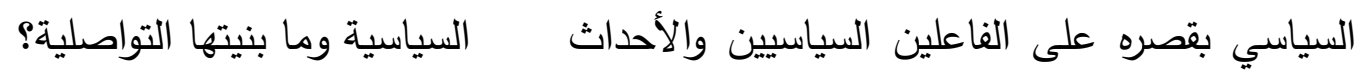

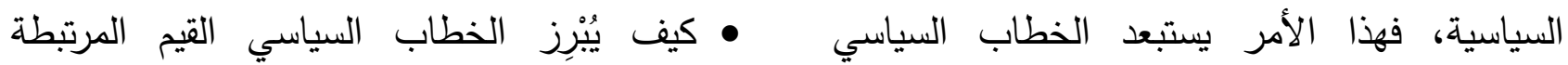
بتاريخ حياة الفرد، وبتراثه أو الجماعة الثقافية التي لتئي اليومي الذي هو جزء من حياة الناس. ينتمي إليها، وما هي انعكاساته على الآخر؟

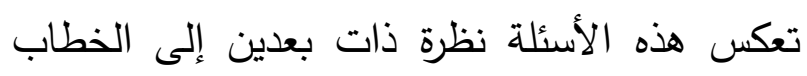

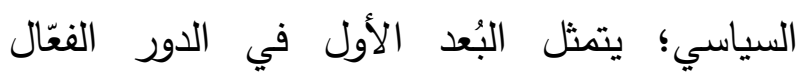
للخطاب السياسي السعودي في خدمة قضايا المملكة

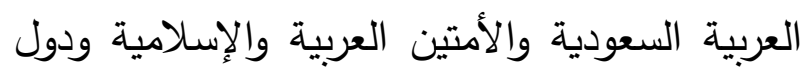
العالم (محتوى الخطاب)، ويرتبط البُعد الثاني بالجوانب التأثيرية في مستوياتها اللغوية والأسلوبية (شكل الخطاب)، وكيفية تضافر شكل الخطاب

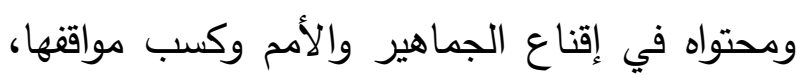
تلقيًا واستجابةً وتأثيرًا. وللإجابة عن الأسئلة السالفة، ودراستها في بُعديّ وليّات

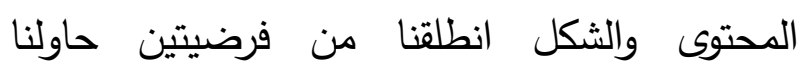
تمحيصهما في المجال التطبيقي من هذه الدراسة صغناها على هيئة سؤالين كبيرين: - هل تعس المستويات اللغوية والحجاجية والأسلوبية وغيرها في الخطابات السياسية للأمير سعود الفيصل التصورات الفكرية المكونة لهويته بناء على ذلك فإن التساؤل عن ماهية الخطاب التهاب السياسي وأخلاقياته ليست ترفًا ذهنيًا، بل هي مسألة فئل

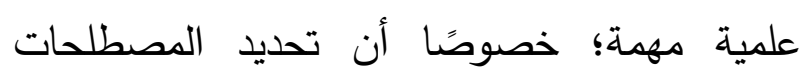

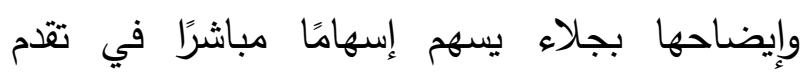

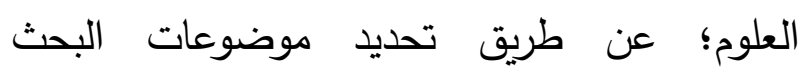
وحدودها، وتجنب الخلط والتداخل الذي يُضيع الكثيرَ

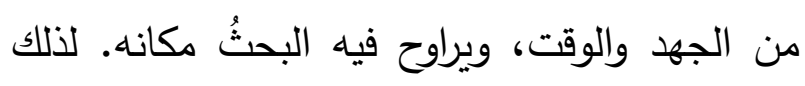
يحاول هذا البحث أن يحدد ماهية الخطاب السياسي وليروح فيه ليحكانه وقضاياه الاستراتيجية، من خلال الدراسة النقدية والسيميائية للخطاب السياسي السعودي وتحديدًا خطابات الأمير سعود الفيصل رحمه الله. تتفرع عن الفئه الإشكالية السابقة الأسئلة الآتية: • ما العلاقة بين اللغة والسياسة؟ الإلئه الاتية ما الذي يجعل من خطاب ما خطابًا سياسيًا؟ • كيف يُبنى الخطاب السياسي عند الأمير سعود الفيصل سيميائيًا؟ • كيف استطاع خطاب الأمير سعود الفيصل فئل فياتل صياغة نموذج سياسي قادر بمفاهيمه وبآلياته 
وضع حد للحرب الأهلية اللبنانية، وكان عرّاب اتفاق

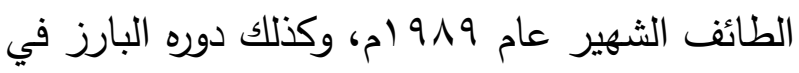

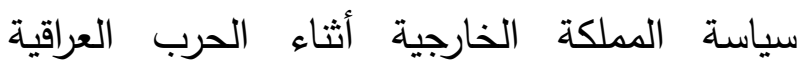
الإيرانية، وفترة الغزو العراقي للكويت، وخلال حرب الخليج التي تبعته والتي أدت إلى تحرير الكويت. كما ساهم في تأسيس مجلس التعاون الخليجي

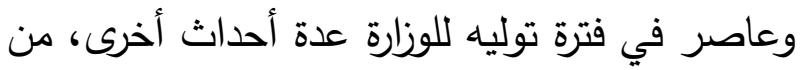

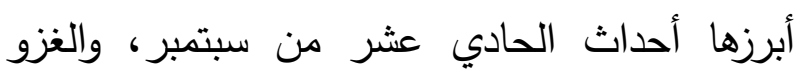

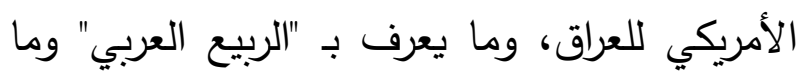

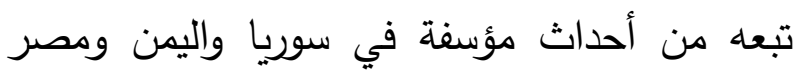

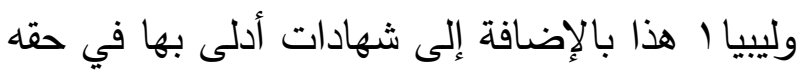

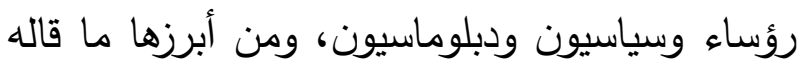
جون كيري، وزير الخارجية الأمريكية، "الأمير سعود ودئه الفيصل لم يكن فقط أقدم وزير خارجية في العالم، بل كان من بين الأكثر حكمة ودهاءً." وما قاله ميخائيل غورباتشوف، آخر رؤساء الاتحاد السوفيتي، لهاء لهاء "الو كان لدي رجل كسعود الفيصل، ما تفكك الاتحاد السوفيتي وانتهى." وقال عنه ديفيد ميليباند وزير الخارجية البريطاني السابق "سعود الثيصل يستطيع أن يحصل على ما يريد ومنح السعودية قوة خارجية

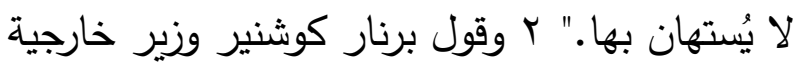

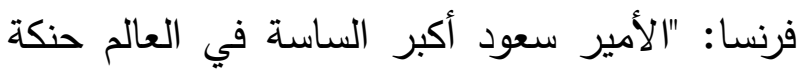

1 ـ للمزيد من التفصيل ينظر كتاب: سعود الفيصل حياته وشخصيته.. رؤاه

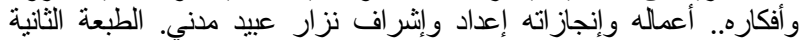

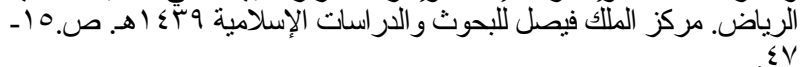
2 - https://fhras.net/47217/.
- هل ليؤدي الخطاب السياسي للأمير سعود الفيصل في بعده اللغوي دورًا كبيرًا في عملية جذب لبدي انتباه مختلف المتلقين وإقناعهم والتأثير فيهم؟ إن المحفّز لاختيارنا هذا الموضوع "دلالات الخطاب

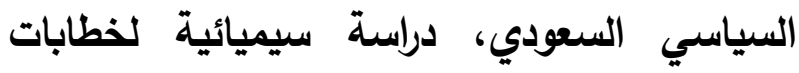

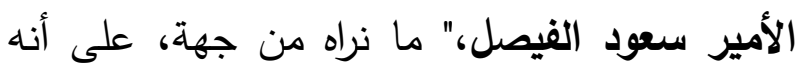

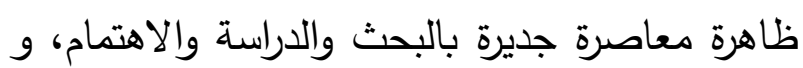
من جهة أخرى، ما تحظى به شخصية الأمير سعود الفيصل من أهمية ووضع اعتباري في الأوساط السياسية المحلية والإقليمية والدولية؛ حيث ترأس وفد المملكة العربية السعودية في العديد من الاجتماعات الخاصة بالقمم العربية والإسلامية بالنيابة عن ملوك البلاد، بالإضافة إلى رئاسته الدائمة لوفد المملكة للاجتماعات الخاصة بوزراء الخارجية العرب والمسلمين وكذلك اجتماعات الجمعية العامة للأمم المتحدة السنوية للفترة التي قضاها بوصفه وزيرًا للخارجية والتي قضى فيها الأمير سعود الفيصل أكثر من · • سنة، وهي أطول

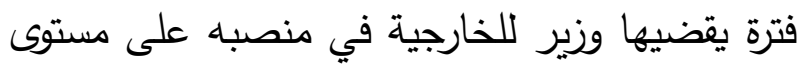

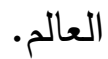
عاصر خلالها أربعة ملوك: الملك خالد، الملك فهد، الملك عبد الله، طيب الله ثراهم ثم عاصر خادم الحرمين الشريفين الملك سلمان بن عبدالعزيز حفظه الله.

اهتم الأمير سعود الفيصل بالقضية الفلسطينية أيّما

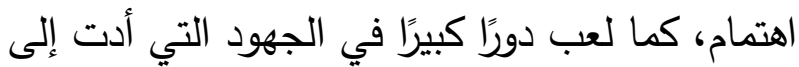


وحكمة". أوذات حوار سُئل الرئيس العراقي صدام وبما أن دراستتا سوف تلقي الضوء على مدى إسهام

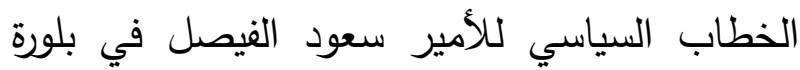
منطق سياسي حكيم في أبعاده الدولية والعربية والمحلية، وفي إبراز الدور السياسي السعودي الفاعل في صناعة القرارات التاريخية، فقد اعتمدنا على ولى نماذج من لسانيات النص وأخرى سيميائية ونقدية للخطاب إطارًا تحليليًا، وجاءت مباحثه على النحو

- المبحث الأول: الخطاب السياسي وعلاقاته

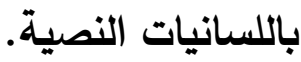

- المبحث الثاني: الاستراتيجيات الخطابية وقوتها الدلالية في تحليل وتأويل خطابات الأمير سعود

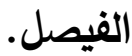

- المبحث الثالث: تحليل الممارسة الخطابية في خطابات الأمير سعود الفيصل. - - - - استنتاجات

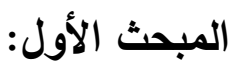

1- الخطاب السياسي وعلاقاته باللسانيات النصية ما الخطاب السياسي وما صلته باللسانيات واللسانيات النصية؟ يبدو من المتعذر اليوم إعطاء تعريف دقيق للخطاب السياسي، ولعلّ ذلك راجع إلى ما يلي: - الخطاب السياسي يقع على حدود تخصصات متعددة أبرزها تخصصين اثثين هما: اللسانيات وعلم السياسة. وكل تخصص منهما يركز على مظهر ايرها

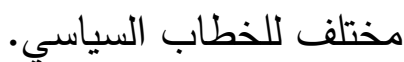
حسين من الرجل الذي تخشاه... ابتسم فقال: سعود

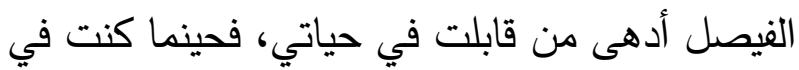

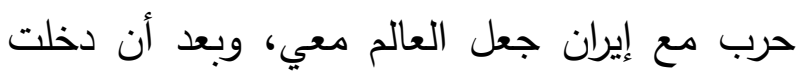
الكويت قلب العالم ضدي!" ب وقال عنه أيضا وزير الخارجية الفرنسي الأسبق هيرفيه دو شاريت: "سعود الفيصل طبع الدبلوماسية السعودية بطابعه خلال سنوات طويلة يحسده عليها كثير من وزراء الخارجية. وإن السعودية التي خدمها الفيصل وزيرًا للخارجية لعبت دورها كاملا كقطب للاستقرار والأمن في الشرق الأوسط." وأضاف إن الأمير الراحل كان

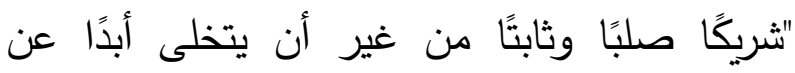
الكياسة واللطف في التعاطي مع الآخرين."ب وبهذه الكلمات وصف وزير الدولة لشؤون الثرق الأوسط الشع البريطاني السابق أليستر بيرت الأمير سعود الفيصل

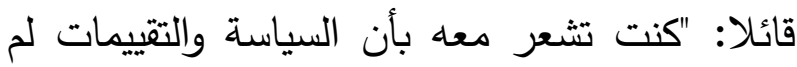

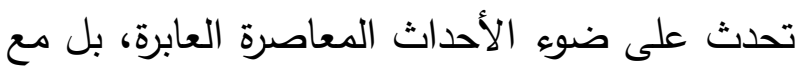
شعور بأن هناك جدولا زمنيًا أطول بكثير من ذلك الك الذي يعتمده الآخرون، خاصة الحكومات الغربية.

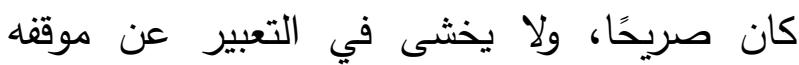
بوضوح، وكان لديه آراء واضحة حول الصواب والخطأ." ؛ وصوح،

1 - https://sabq.org/LmuGHe

2 - https://fhras.net/47217/.

3 -https://www.orient-news.net/ar/news_show/88858

4 -https://www.orient-news.net/ar/news_show/88858 
للنص والحليث نفسه، بل ينبغي أن تتضمن أيضًا نظرة نسقية للسياق وعلاقاته بالبنيات الخطابية"'

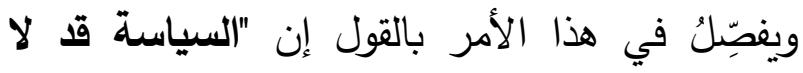
تتضمن فقط كل الفاعلين والأحاث والمقابلات والأوضاع والأفعال والخطابات السياسية الرسمية وغير الرسمية، بل أيضا وبصورة مجردة كثيرا:

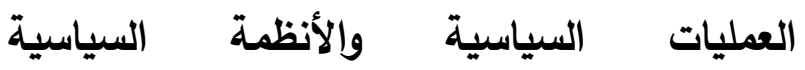
والإيديولوجيات السياسية والعلاقات السياسية". ‘ ويرى أنه لا يمكن فهم الخطاب السياسي دون فهم حقل السياسة الذي يعد مقولة عامة تحوي العديد

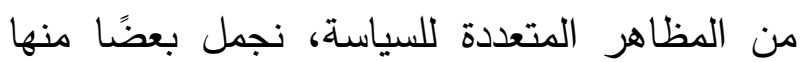

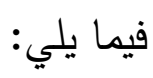
• الأنظمة السياسية: هي الأنظمة التي تدلُ على تنظيم السلطة وتوزيعها ومبادئ صناعة القرار . • القيم السياسية: هي القيم الثقافية المشتركة والنمطية للأنظمة السياسية كالحرية والتضامن

$$
\text { والتسامح... إلخ. }
$$

• الخطاب السياسي: يعدُ النموذج الخاص للفعل والتفاعل السياسيين. إنه طريقة بارزة لـ "ممارسة السياسة". وفي الواقع تعتبرُ معظم الأفعال السياسية

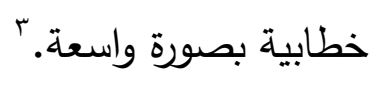

1- Van Dijk, Teun (1997). what is Political Discourse Analysis? In Jean Blommaert \& Chris Bulicaen (Eds.), Political Linguistics. Amsterdam: Benjamin. P.15.

2 - ibid, p. 15. "ثُرجم المرجع عن طريق مركز المهند للترجمة .

3 -Van Dijk, Teun (1997). what is Political Discourse Analysis? P.16.
- الخطاب السياسي يشتمل على مصطلحين يعدًان من أكثر المصطلحات تداولا في الخطابات العلمية والاستعمالات اليومية، وهما مصطلحا: "خطاب"،

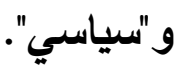
- غياب اتفاق كلي حول معنى الخطاب والسياسة، لا سيما حينما يجتمعان في عبارة واحدة (الخطاب (السياسي). ومن المعلوم للى الباحثين في العلاقة بين اللغة والسياسة أن الاهتمام بالخطاب السياسي المعاصر كان نتيجة الاهتمام بلغة السياسيين ولغة الإعلام في الأحداث السياسية، والتركيز على الدور الذي تمتلكه اللغة في تثكيل السياسة. لذلك انكب الباحثون

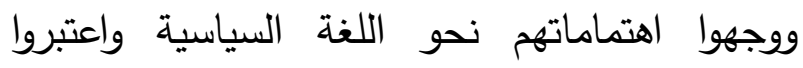
الدراسة اللسانية للتواصل السياسي تخصصًا فرعيًا للسانيات. وقد استعملوا عبارة اللسانيات السياسية

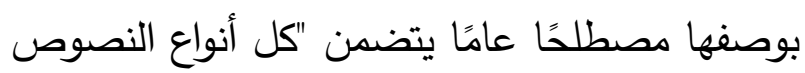
النموذجية للسياسة بالإضافة إلى استعمال الأدوات المعجمية والأسلوبية واللغوية التي تميز الأحاديث حول السياقات السياسية. ولعلّ دراسة تون فون

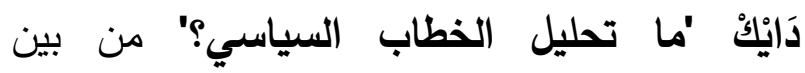
الدراسات الهامة في تعريف الخطاب السياسي. والبعد المميز لـقترح فون دَايْكُ يتمثل في إدماجه لعنصر السياق في تعريفه للخطاب السياسي، وهو أمر يعبر عنه بالقول: "تبعا لوجهة نظرنا التحليلية للخطابِ يقترحُ التعريف السياقي أن دراسة الخطاب السياسي ينبغي ألا تقتصر على الخصائص البنيوية 
- الأدوات السيميائية (الصور والعلامات والرمز

والتحليل السيميائي)(ب)

ويحتوي تحليل نص ما حسب فيركلف على سبعة

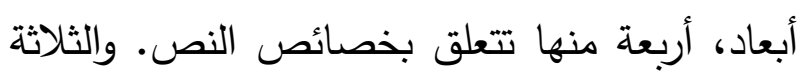

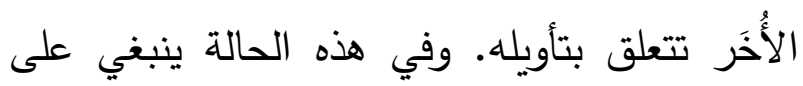
التحليل اللساني أن يضع في اعتباره مفردات النص لتصني

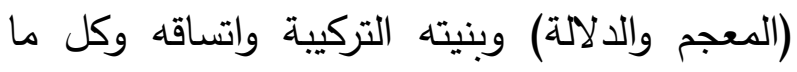
يتعلق بالبنية العامة للنص. ويستند تأويل الخطاب ولتئه

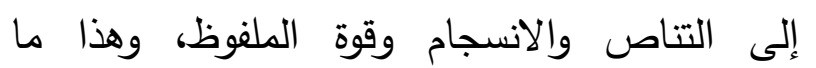
يوضحه الجدولان التاليان:(r)
وبناء على تحديد حقل السياسة يعرف تون فون دَايْكُ الخطاب السياسي بأنه "فعل سياسي ووعاء

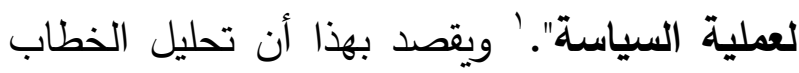
السياسي يستند بالضرورة إلى نظرية لسانية تعد

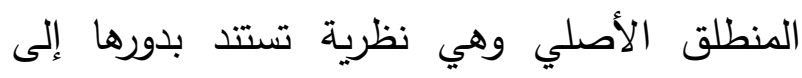
تخصصات فرعية لا سيما النظريات التداولية ولسانيات النص، ثم تخرج بعد ذلك إلى نظرية اجتماعية وثثقافية. ويعد الباحث اللساني آرمين بوركهات من الرواد الأوائل الذين ساهموا اليوم في الئماعيه تأسيس تخصص علمي هو اللسانيات السياسية. حيث حدد بعض الإجراءات المنهجية لتحليل الخطاب السياسي والتي يمكن أن نوجزها على الألى

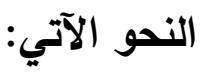
- الأدوات الدولاتية المعجمية (تحليل الكلمات

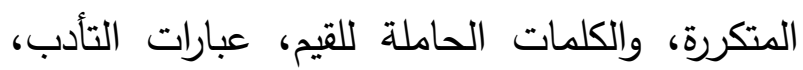
والتعدد الدلالي للأفكار والكلمات). - إجراءات تركيبية ودلالية نصيّيَّة (مثل تحليل المجازات والتقابلات الدلالية واستراتيجيتي الحذف ودليه والذكر أو الفصل والوصل). - الأدوات التداولية واللسانية النصية (مثل تحليل

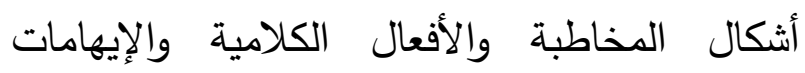

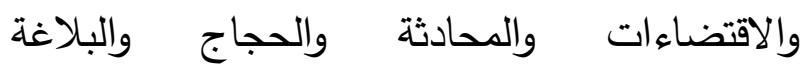
والاقتباسات والتتاص).
2 -Wodak, Ruth (2009a). The Discourse of Politics in Action: Politics as Usual. Basingstoke, UK: Palgrave Macmillan.p.7. "تُرجِم المرجع عن طريق مركز المهند للترجمة المَّة

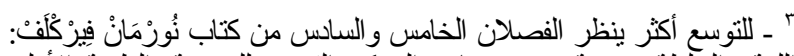

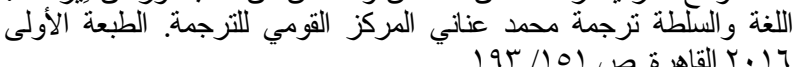

1 - ibid, p. 20. "تُرجم المرجع عن طريق مركز المهند للترجمة 


\begin{tabular}{|c|c|}
\hline دلالاتها في تحليل الخطاب & أدوات وصف بنية النص \\
\hline 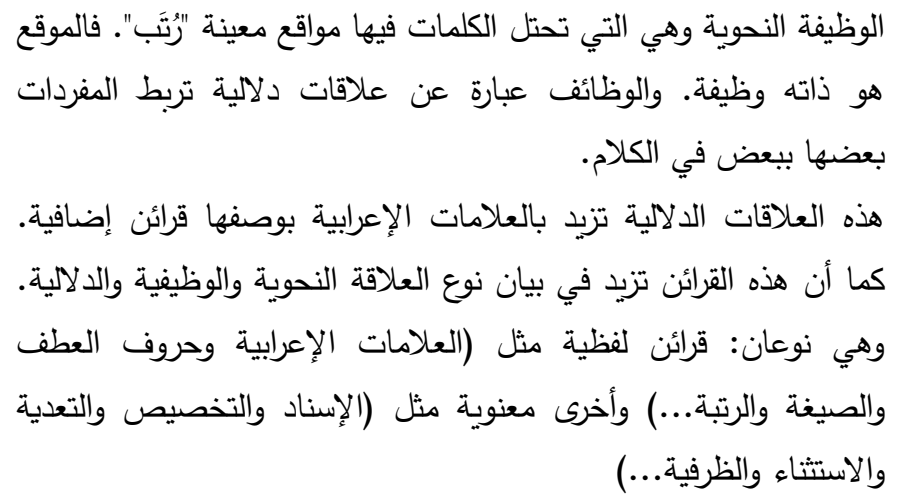 & النحو (التركيب) \\
\hline 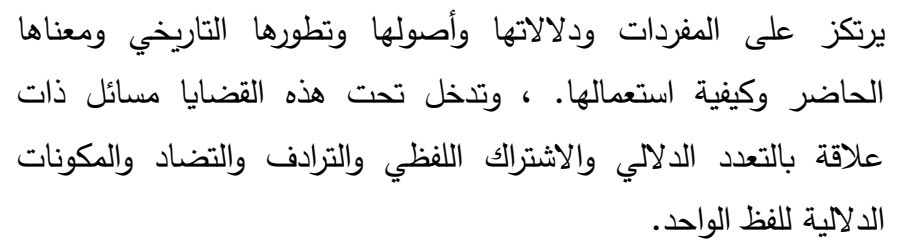 & المعجم \\
\hline 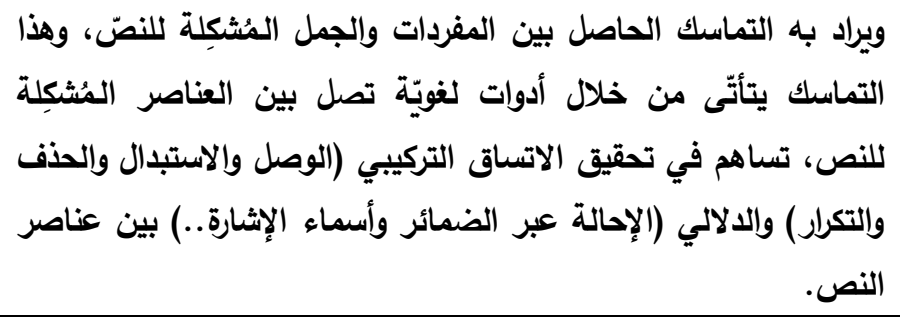 & اتساق النص \\
\hline يراد بها الإشارة إلى البنية الكلية للنص ثم الكيفية التي يتم بها ربط إلت إدارة التحدث في الخطاب. & البنية العامة \\
\hline
\end{tabular}

\begin{tabular}{|c|c|}
\hline دلالاتها في تحليل وتأويل الخطاب & أدوات النص المؤثرة على تأويله \\
\hline نبرة الجملة: وعد، تهديد، اقتراح، أمر ، شكوى & قوة الملفوظ \\
\hline 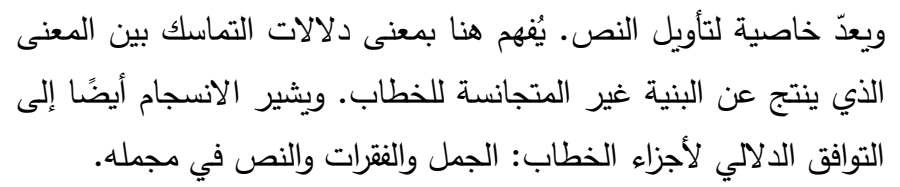 & 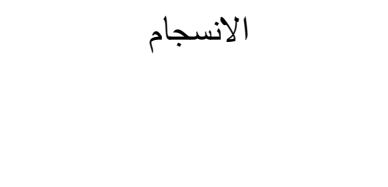 \\
\hline 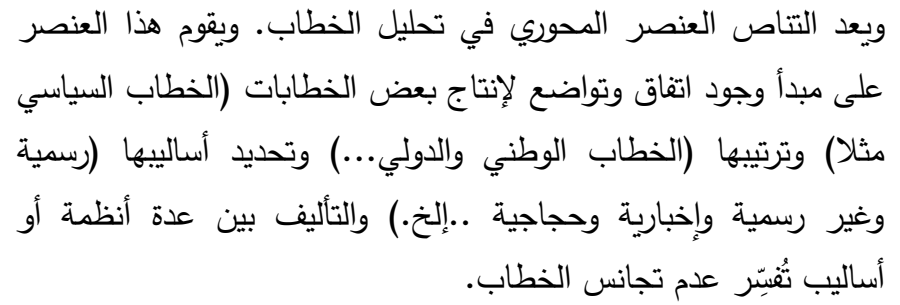 & 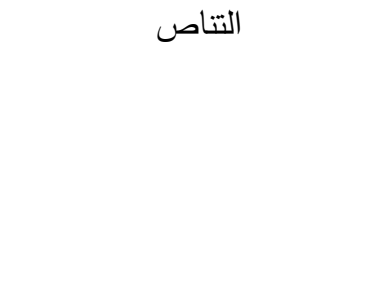 \\
\hline
\end{tabular}


ونلاحظ من خلال هذه الإجراءات أن مهمة تحليل المبحث الثاني:

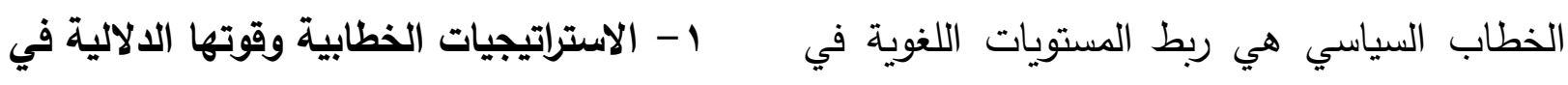
الخطاب السياسي بهذه الوظائف الاستراتيجية. وهذه تحليل وتأويل خطابات الأمير سعود الفيصل.

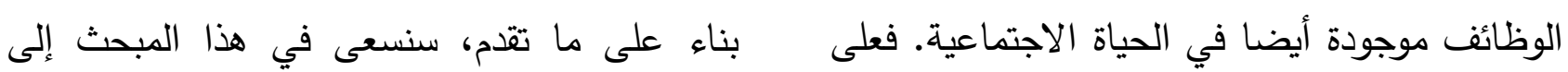

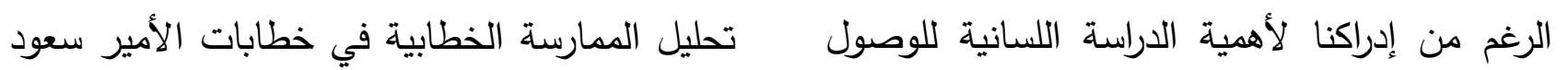

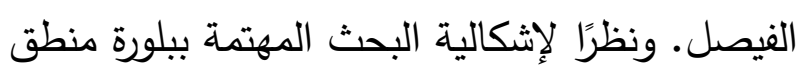
سياسي حكيم ومغاير في أبعاده الدولية والعربية

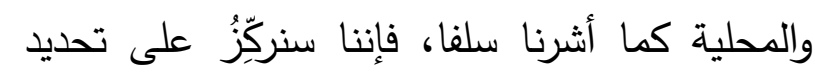
الاستراتيجيات الخطابية وقوتها الدالية في تحليل وتأويل خطابات الأمير سعود الفيصل، باعتمادنا نهج فيركلف والدراسات السيميائية التي تولّي أهمية خاصة للمعجم والتركيب واللغة، إلى جانب اهتمامها بتحليل العلاقات والاستراتيجيات داخل سلطة النص. وتكمن أصالة هذا النهج في مزجه بين المقاربة النصية والمقاربة النقدية للخطاب ممّا يعطي تعريفًا جديدًا للخطاب وهو تعريف يتأطر ضمن الأبعاد الثلاثية الآتية: جايداب

$$
\text { - }
$$

- الممارسة الخطابية -

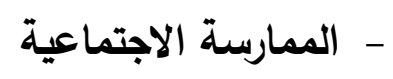

ب - ماريان يورغنسن- لويز فيليس: تحليل الخطاب النظرية والمنهج. ترجمة

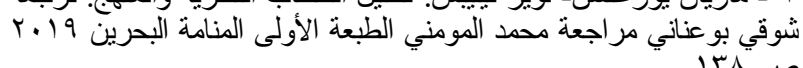
إلى نتائج مهمة حول كيفية اشتغال العمليات الخطابية لغويًا في نصوص معينة، إلاً أن الدراسة

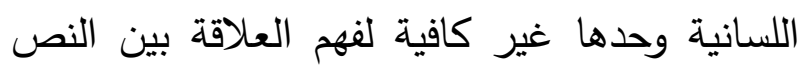

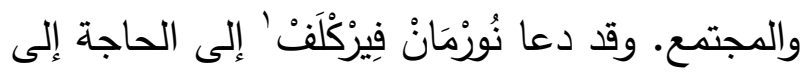

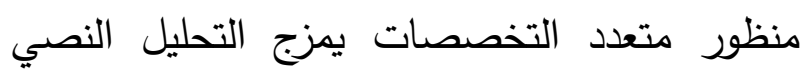
بالتحليل الاجتماعي والثقافي؛ وذلك عبرد التركيز

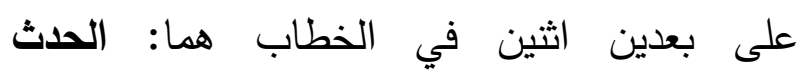
التواصلي ونظام الخطاب، وهو ما سعى التحليل النقدي للخطاب والدراسات السميائية الثقافية المعاصرة إلى تبنيه منهجًا للاراسة والتحليل. حيث

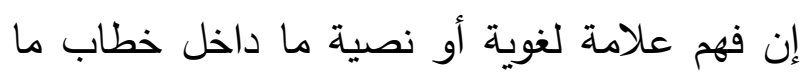
(خطاب سياسي) سواء في بنيتها الداخلية الشكلية

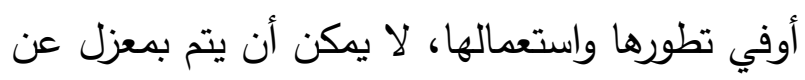

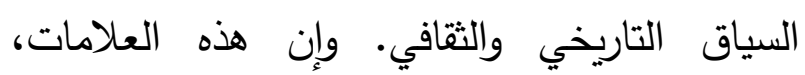

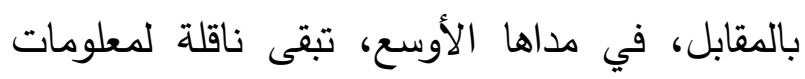

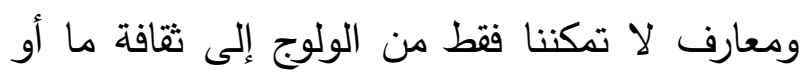
حقبة زمنية ما، ولكنها تشكِّل صورة مصغرة أو أثرًا دالاّ على حدث ثقافي بمعارفه وقيمه وجماعة ولئه

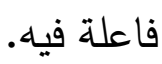

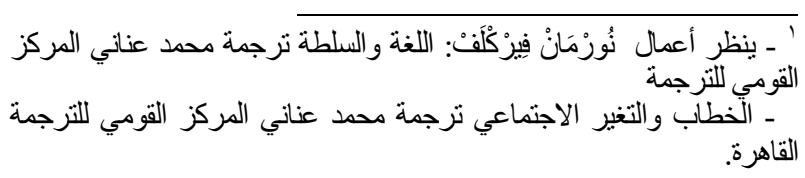




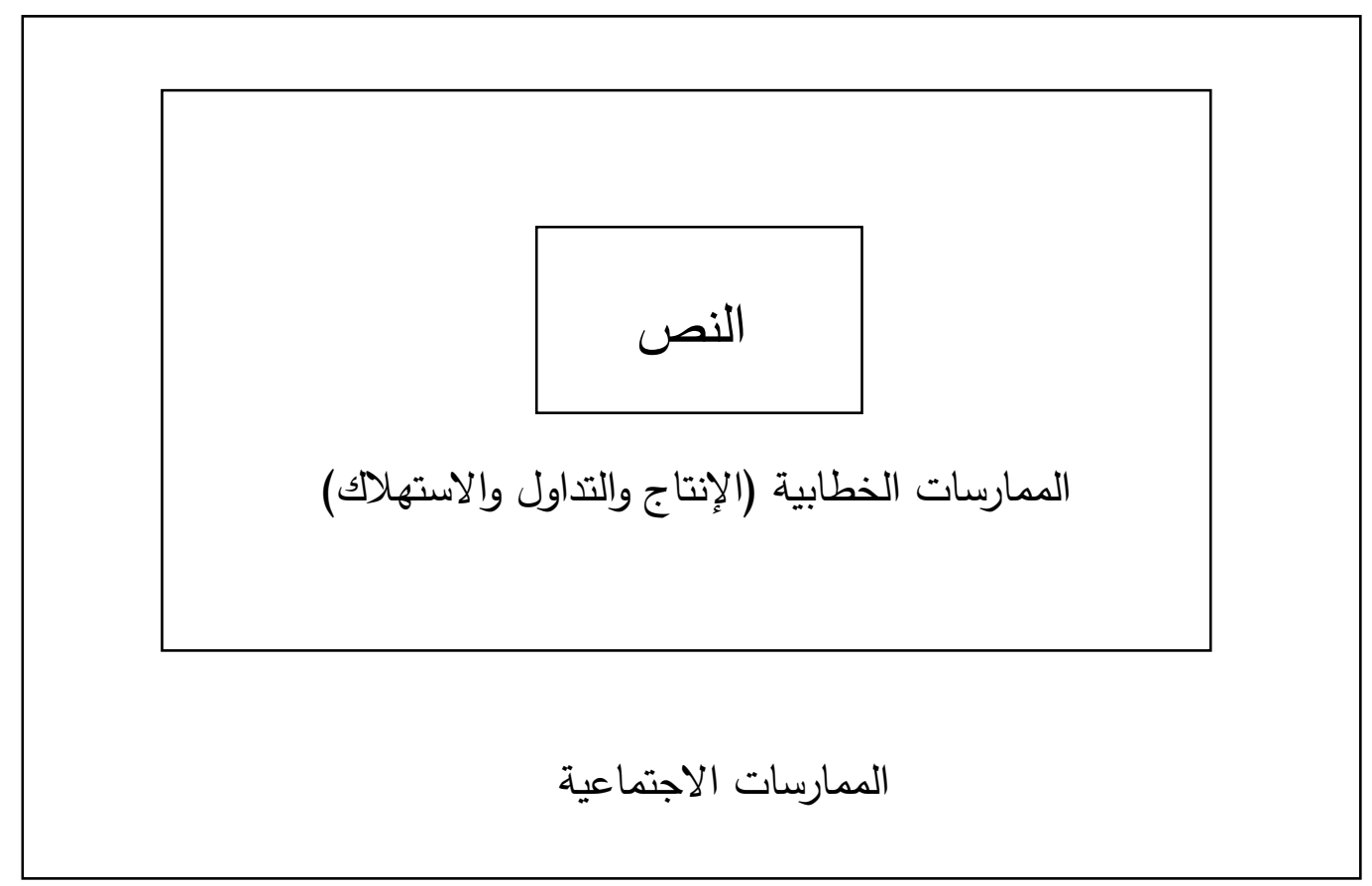

تربط هذه المنهجية التحليل الوصفي للنص بتأويله للقضايا الكبرى التي تهم الأمم والثعوب. يقول

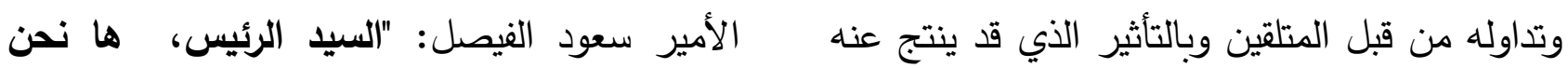

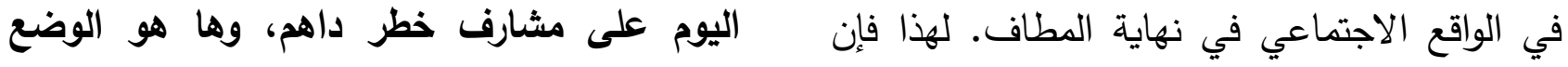

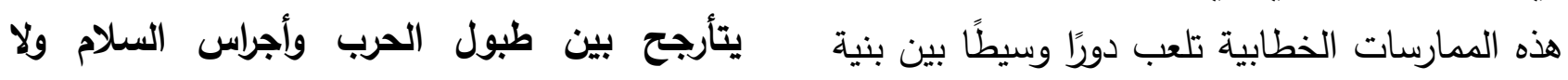

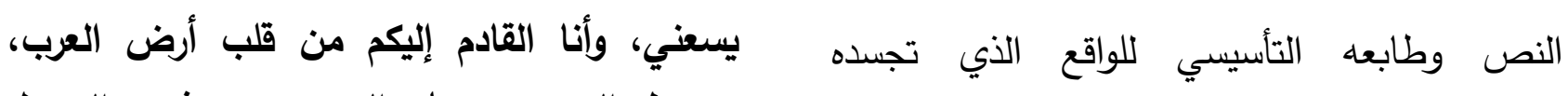

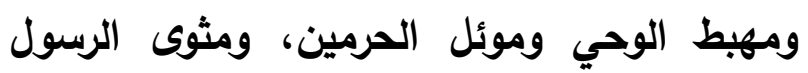
الممارسات الاجتماعية.

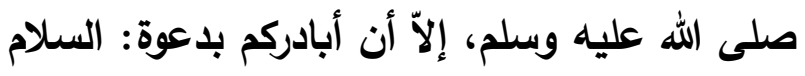
عليكم، وهي دعوة السلام والمودة التي يتبادلها كل

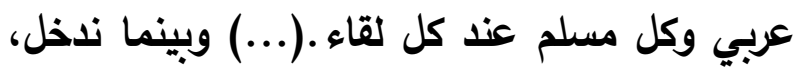

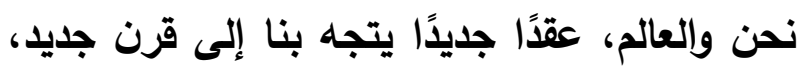
هو القرن الواحد وإلعشرون، فإنتا، وقد شاركنا في

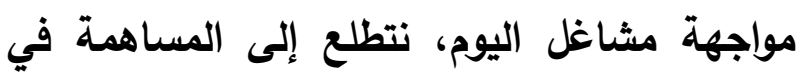

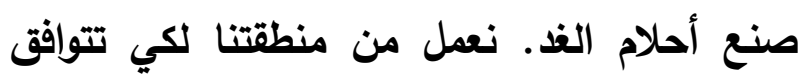
خطوات النظام العربي المتجدد مع النظام العالمي

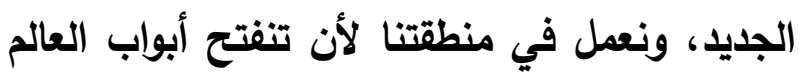

وبالعودة إلى خطابات الأمير سعود الفيصل في

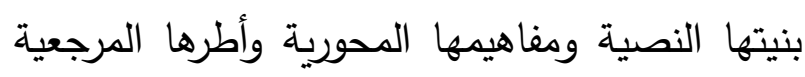
والقضايا الكبرى التي تتناولها، فإننا نلمس امتتال كل

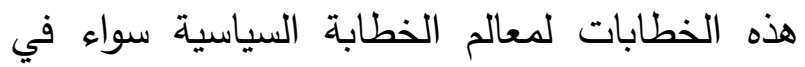

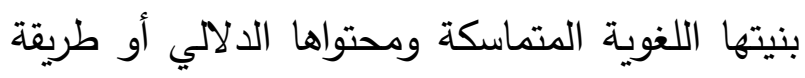

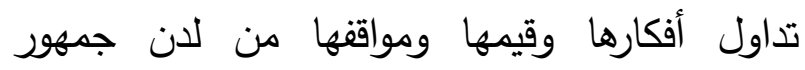
المتلقين بطريقة إقناعية ويمكن التدليل على ذلك من خلال تتاول الأمير سعود الفيصل في خطاعله وبناته 
الملاحظة دومًا، ويركزان على ضمير المتكلم المفرد 'أنا' والجمع 'نحن'، وضمير المخاطب المفرد 'أنت' والجمع 'أنتم'. ويشيران إلى أن ضمير 'أنا' قد يدل

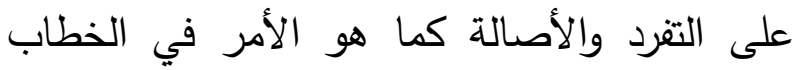
السياسي ويعكس الرؤية الشخصية للفاعل السياسي

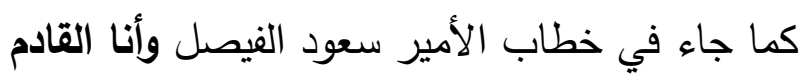
إليكم من قلب أرض العرب، ففعل القدوم يملك دلالة

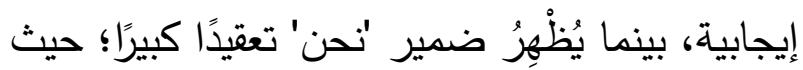

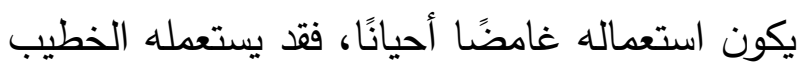
للدلالة على نفسه وعلى شخص آخر أو أشخاص آخرين غير متضمنين في خطابه، وهم الأمة العربية

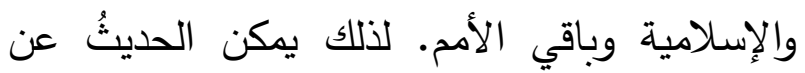

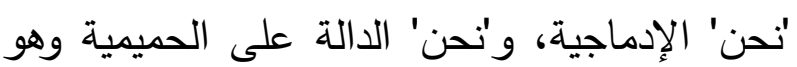
ما نلمسه في خطاب الأمير سعود الفيصل في قوله:

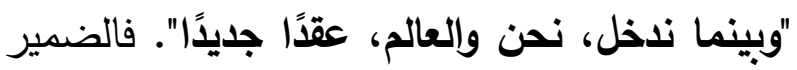

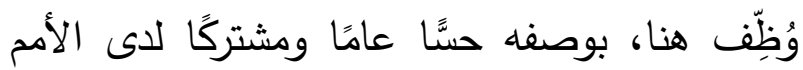
جميعًا أو صوت الواجب الإنساني. لذلك فكل جملة من جمل خطابات الأمير سعود الفيصل تشكل نصًا كما يذهب إلى ذلك الباحث اللساني هاليداي بحكم العلاقات التي تربط بين عناصرها، سواء كانت علاقات قبلية أو بعدية.

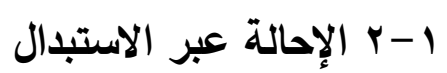
والاستبدال إجراء يتم داخل النص، حيث يحل عنصر محل عنصر آخر كلمة أو جملة. ويعتبر Kress \& Tony Trew. (1979). Language and Control. Lُرجم المرجع عن طريق مركز " .

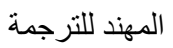

r ـ محمد خطابي لسانيات النص مدخل إلى انسجام الخطاب الطبعة الأولى 1991 المركز الثقلفي العربي الدار الييضاء ص. با.
الجديد على تطلعات الدول وأماني الثعوب. عالم

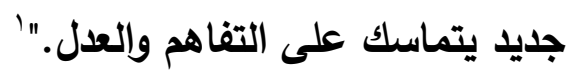
1- المظاهر النصّية للخطاب 1- 1 الإحالة عبر الضمائر

تؤدي لغة الخطاب عند الأمير سعود الفيصل، دورًا

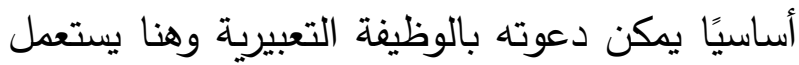

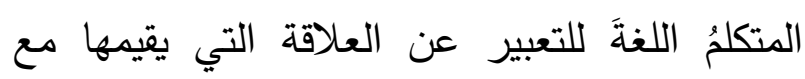
المستمعين إليه، وبصفة خاصة للتعبير عن الدور

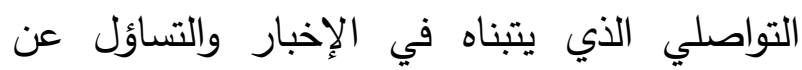

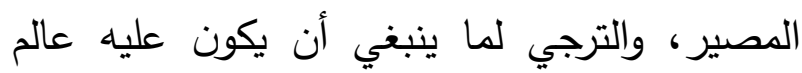
الغد. وقد سلك فيه الخطيب نوعًا من التدرّج حفاظًا

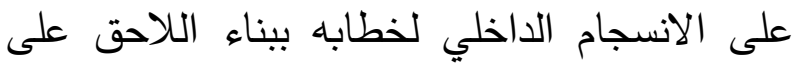
السابق، وبتقابلات دلالية ضدية بين مفرداته الحرب

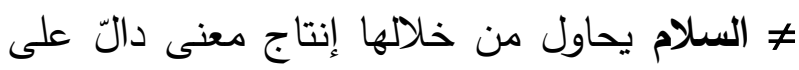

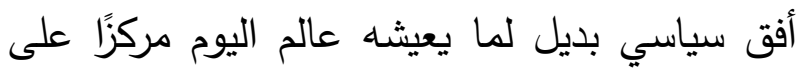
فلسفة الحلّ للمعضلات بدل فلسفة استهلاكها وإعادة تدويرها. وقد تم توظيف أبنية لسانية، دلالية

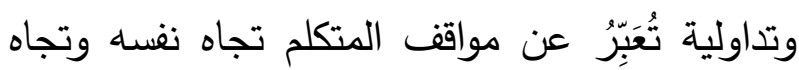
مخاطبيه وتجاه موضوعهم، ومن مظاهر اتساق الخطاب السياسي عند الأمير سعود الفيصل، طريقة ومن مظناه توظيفه للضمائر الثخصية بما هي عنصر إحالي، سواء إحالة مقامية خارج النص أو إحالة نصية داخل الخطاب تشير إلى السابق من الكلام وما يليه.

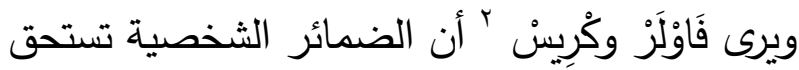

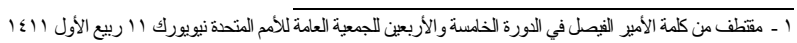

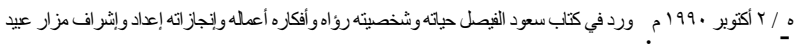

2 - Fowler, Roger \& Gunther Kress (1979). Critical Linguistics. In Roger Fowler, Bob Hodge, Gunther $=$ 
والاستعمالي، أي قيمته وقوته الإنجازية. بمعنى

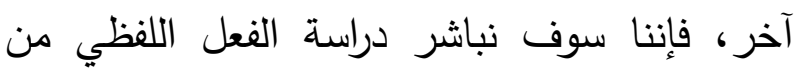

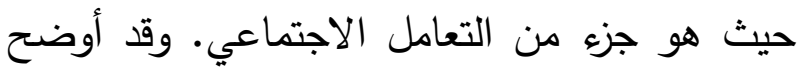
فيلسوف اللغة الإنجليزي جون أوستين كيف أن اللغة هن يمكن أن تستخدم لتنجز وعدًا أو تصريحًا أو تهديدًا أو مقايضة إلى غير ذلك من الأفعال التي يقترن القول فيها بإنجاز الفعل. بمعنى أخر يعدّ فعل الكلام

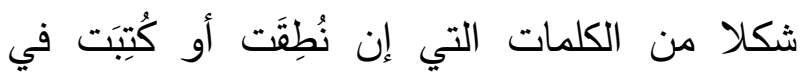

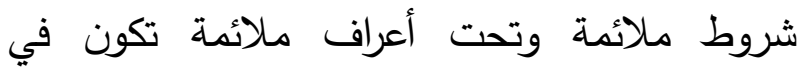
الحقيقة إنجازًا لفعل معين، ويسمح تحليل ولحيل الأفعال

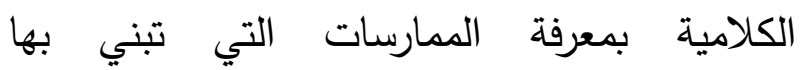
المجتمعات أفكارها وقواعدها. إنّ التتوع المصاحب لعمل الفعل الكلامي، سواء في القول أو في مقصود القول أو في التأثير، جعل لتوعل

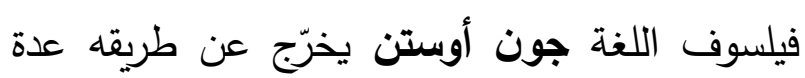
تخريجات كلها تتصب أساسًا في واقع الفعل الكلامي الذي يحوي في باطنه على قوة إنجازية تختلف

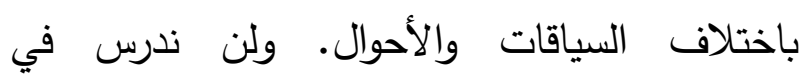
خطابات الأمير سعود الفيصل الأفعال الكلامية في صورتها المجردة بل انطلاقًا من البعد الاجتماعي الذي تحاول إنجازه من قبيل: التأكيد أو السؤال، أو الو

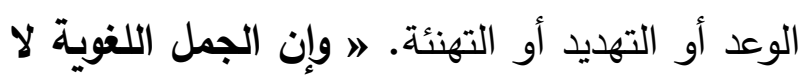
تنقل مضامين مجردة، وإنما تؤدي وظائف تختلف باختلاف السياقات والمقامات المتنوعة.«"وّسنركز
الاستبدال وسيلة أساسية معتمدة في اتساق النص.

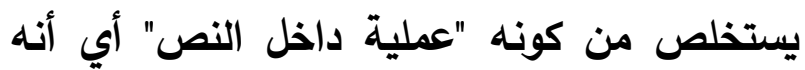
نصي، على أن معظم حالات الاستبدال النصي لونه

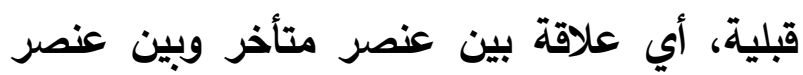

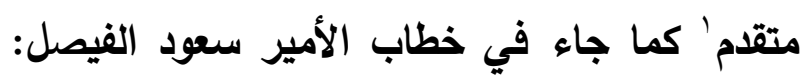
وبينما ندخل، نحن والعالم، عقدًا جديدًا يتجه بنا إلى قرن جديد، هو القرن الواحد والعشرون، وإن العلاقة بين هذه العناصر المستبدلة يتحكم فيها

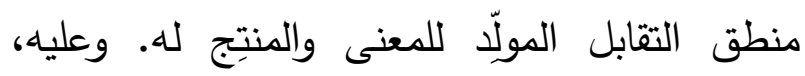
"فالاتساق هو "ذلك التماسك الثديد بين الأجزاء المشكِلة لنص/خطاب ما، ويهتم فيه بالوسائل اللغوية (الثكلية) التي تصل بين العناصر المكونة

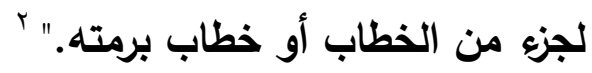
1-r تحليل الأفعال اللغوية إن اللغة ليست بنيات تركيبية ودلالية فحسب، بل

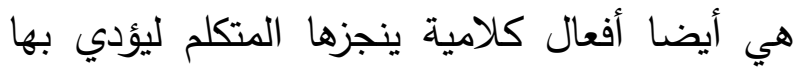
أغراضًا ومقاصد مباشرة أو غير مباشرة؛ إنها إنجاز يطمح المتكلم من خلاله إلى إحداث تغيير معين في سلوك المخاطب بالفعل أو بالكلام. وإن الكلام بدون شك - تبادل للمعلومات، وهو إنجاز لأفعال مبنيّة وفق مجموعة من القواعد من شأنها تغيير وضعية المتلقي وتغيير منظومة معتقداته وأفكاره. ويترتب على ذلك أن فهم الكلام وإدراكه يعني تحقيق وتفعيل مضمونه الإخباري وتحديد غرضه التداولي 
والالتزام بتتفيذه. من هذا المنظور ندرك أنَّ لغته تحمل بصفة ذاتية وجوهرية وظيفة حجاجية، أي أنَّ هذه الوظيفة مشار لها في بنية أقواله ودلالاتها. وهي ونهاي أفعال كبرى تحققها كل خطاباته وفق سياقاتها التداولية ومقاماتها التخاطبية وفعلها الاجتماعي والسياسي، وتختزل في قضايا وأطر مرجعية دالّة على: • التصدي للإرهاب الدولي والتأكيا على ضرورة إزالة الأسباب والظروف التي تسمح بتكاثر وإنتشار دعاته وتحقيق أهدافهم. • تحميل المجتمع الدولي مسؤولياته تجاه القضية الفلسطينية. • الإصلاح داخل المملكة. • إصلاح الأمم المتحدة. • الأزمة النووية. • التعاون مع الدول الغربية وتفعيل آليات الحوار. • تفعيل العمل العربي المشترك. • الإصلاح في العالم العربي. • تطوير عمل منظمة المؤتمر الإسلامي لمواجهة التحديات التي تواجه الأمة الإسدلامية. • تطوير عمل الابلوماسية السعودية. وإن الهدف، في نهاية المطاف، هو بناء نسق

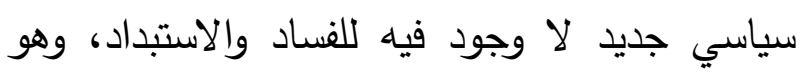

ـ ـ اللمزيد من التفصيل ينظر: استراتيجيات الإفناع السيلسي قراءة تحليلية لخطاب سمو الأمير سعود الفيصل للاكتور مطلق سعود

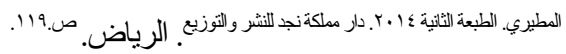

على ما أسماه فون دَايْكُ بـ"الفعل الكلامي العام' أو

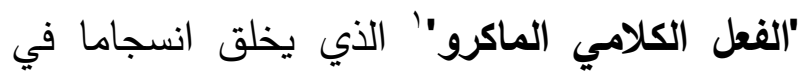

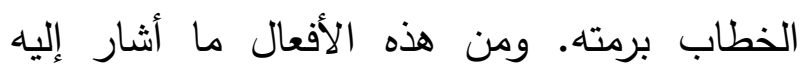
الاكتور أحمد المتوكل في اللسانيات الوظيفية: 'وهي:

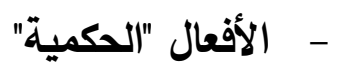
- الأفعال "الأمريةة" - الأفعاله" - - الأفعال "الاكتزامية - الامعيه" - الأفعال "التعبيريـة -

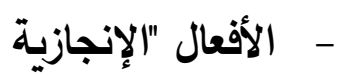
ولقد أشار فان دايك إلى وجود علاقة قوية بين البنية الدلالية الكبرى والفعل الكلامي الإنجازي الثامل، حيث ذهب إلى أن "معنى الخطاب يرتبط ارتباطًا

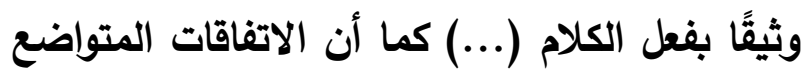

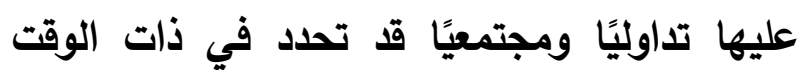
الاختيار الالالي من بين المعلومات المعروضة... فعلى هذا فإن صياغة البنيات الدلالية تكوِن أيضًا وظيفة لبنية تداولية كبرى... وتحدد القضية الكبرى

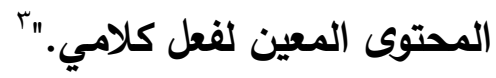
إن الأمير سعود الفيصل في كل خطاباته ومحاوراته لا يتكلم فقط بقصد التأثير على الآخر ، بل إلى حمله على الاقتناع بصحة ما يدعوه إليه والانخراط فيه لإسي

1 -Van Dijk, Teun (1997). what is Political Discourse Analysis? P.14-15.

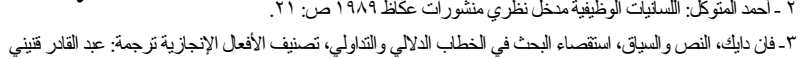

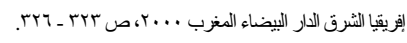


كافة."' لذلك تنال هذه التظيمات الإرهابية نصيبًا

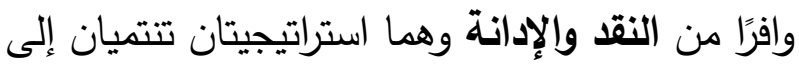
فعل كلامي ماكرو (كلي وشامل) هو نزع الثرعية. ويرتبط بهذا الفعل الكلامي الماكرو فعلان كلاميان

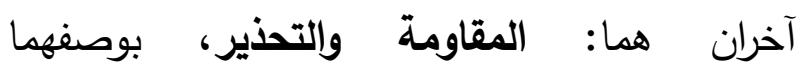
استراتيجيتين خطابيتين للخطاب السياسي، مقاومة السياسات العنصرية والاستيطانية والإرهابية وتحذير

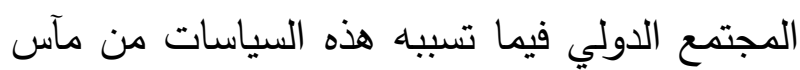
غير مسبوقة شملت تشريد معظم الشعب الفلسطيني. r- إضفاء الثرعية على السياسات العقلانية

\section{والإصلاحية.}

r- تجديد وتطوير الفعل السياسي. وبما أن تحليل الخطاب السياسي يدافع عن ونيريل

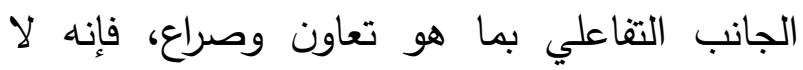
ينبغي أن نغفل الجانب المعرفي كذلك، ما دامت في

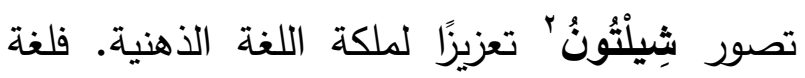
الخطاب السياسي تعدّ انعكاسًا ذهنيًا للأفكار التي لتهي يكوّنها السياسيون عن العالم. فللخطاب السياسي لهي ليسي علاقات خاصة بالمراكز الشعورية للدماغ، تدلّ عليها عمليات لغوية في الخطاب وتعبّر عنها أفعال. وهي عمليات ذهنية (إدراكية ومعرفية، دالة على رغبة أو أونات إحساس) سوف تتم ترجمتها إلى إجراءات لفظية ثم

1 - كلمة الأمبير سعود الفيصل في الكورة العلية الر(79) للجمعية العامة للأمم التخدة في نيويورك. 2 - Chilton, Paul (2004). Analyzing Political Discourse: Theory and Practice. London and New York: Routledge.p.201/205.
نسق يمكن اختزاله في أفعال عامة وكلية بتعبير فون دايك يتم التعبير عنه على هذا النحو: 1- نزع الثرعية من السياسات والإيديولوجيات

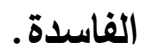
إن المعيار الذي يحدِّدُ الأيديولوجيات الفاسدة هو

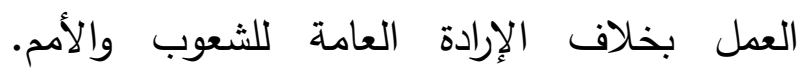
فالتنظيمات الإرهابية المتطرفة والسياسات الإسرائيلية العنصرية المدعومة من القوى الاستعمارية مثلا تحضر كثيرًا في خطابات الأمير سعود الفيصل العربية منها والأممية؛ حيث يقول: "نقف اليوم أمام وضعٍ خطيٍٍ للغاية، فبعد أن كان الإرهاب خلايا أصبح جيوشڤًا. وبعد أن كان يستهدف بؤرًا، تحول إلى استهاف دول يعبث فيها وفي مقدراتها كيفما يشاء.. وأصبح الإرهاب يثكل طوقًا خطيرًا يمتد ليشمل كل من ليبيا ولبنان وسورية والعرلق واليمن. أمام هذه الحقائق الخطيرة، نحن اليوم مطالبون

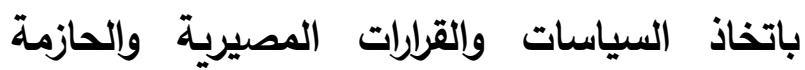
لمواجهة هذه الهجمة الثرسة بكل قوة وحزم، والتحرك الجاد والسريع، آخذين في الاعتبار عنصر الوقت ومغبة التخاذل. من هذا المنطلق، فإنتا نرى أن الحرب على الإرهاب ينبغي أن تكون شاملة، ووفق استراتيجية واضحة مدعومة بخطة تنفيذية

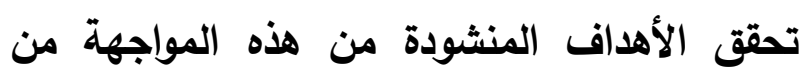
جوانبها العسكرية والأمنية والاقتصادية والفكرية 
إنجازية ومادية. ويطرح شِيلتُون هنا مسألة المشاعر العرب، ومهبط الوحي وموئل الحرمين، ومثثوى السياسية من قبيل: الانتماء إلى بقعة ترابية أو إلى الرسول صلى صلى الله عليه وسلم" والتوجس من الغزاة

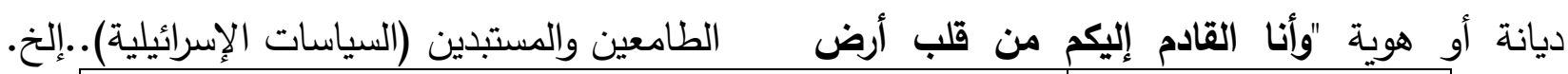

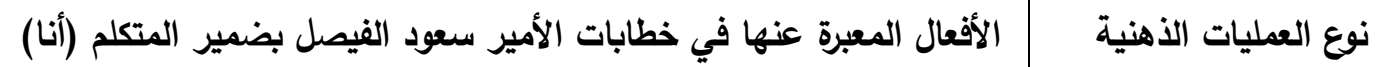

\begin{tabular}{|c|c|}
\hline أو (نحن) & \\
\hline ندرك، نحس، نلاحظ، نسمع، أحس... & إدراكية \\
\hline نفكَّر ، أومن، نتوقَّع، نعتبر ، نعرف، نفهر ... & معرفية \\
\hline 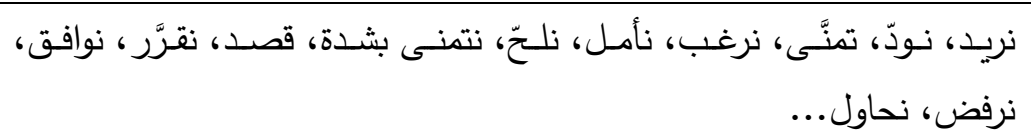 & دالة على رغبة \\
\hline
\end{tabular}

وتعدّ التعابير الصيغية للغة التي يوظفها الأمير ينظر ألجيرداس جوليان غريماس إلى البنية

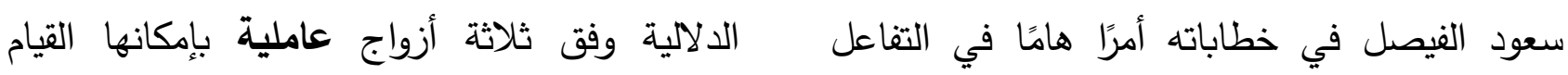

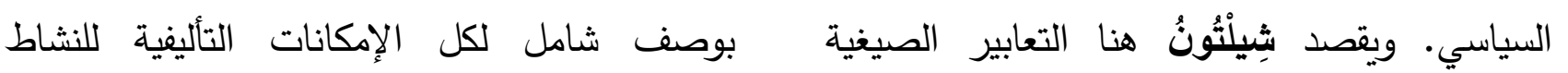

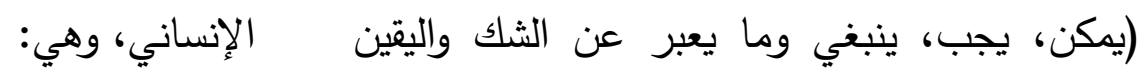

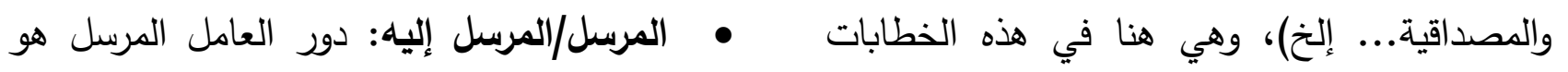

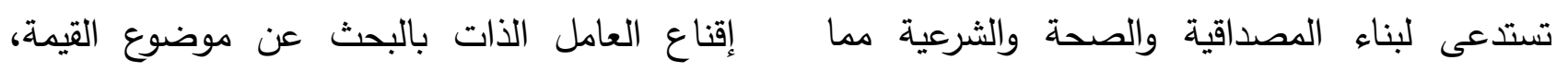
يشكل استراتيجية سياسية سليمة في تصريف والعلاقة بين المرسل والمرسل إليه قائمة على محور

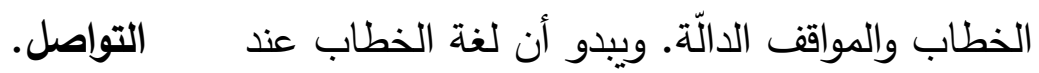

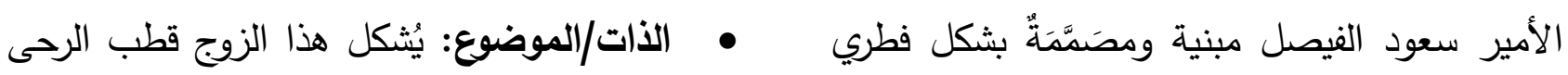

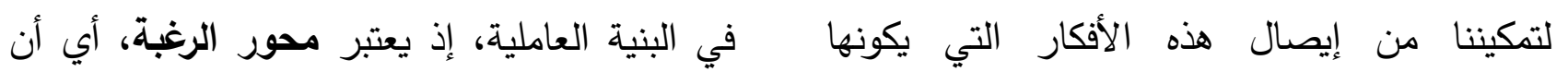

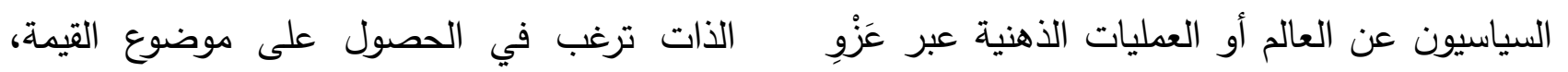

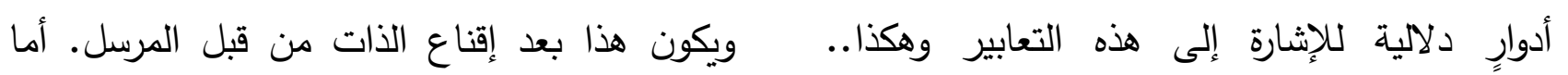

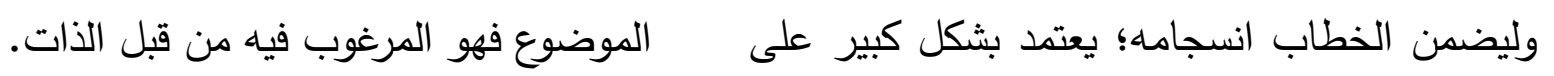

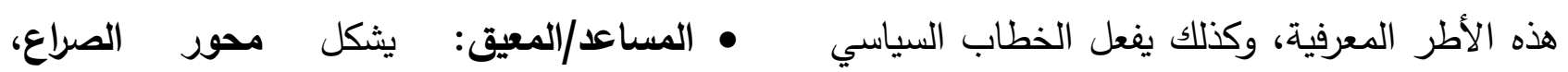

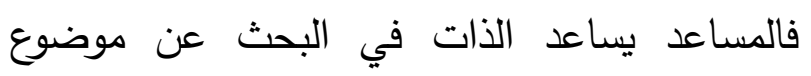

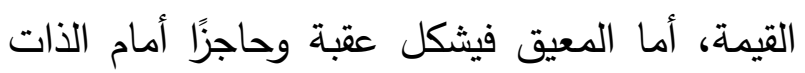
في الحصول على موضوع القيمة. عبر الاعتماد على أطر مفترضة افتراضًا مسبقًا. r- سميائيات الخطاب السياسي : البناء العاملي r- 
سياساتها التعسفية المناقضة لهذه الإرادة؟ متى سوف يتحرك المجتمع الدولي تجاه إسرائيل التي لا زالت تمارس سياساتها التعفية الأحادية الجانب من خلال محاولاتها تهويد القس الثريف وتغيير تركيبته الايمغرافية وارتكاب الانتهاكات اليومية ضد الفلسطينيين من تهجير وطرد وإعتقال تعسفي؟ هذا إلى جانب استمرار سياسات إسرائيل الاستيطانية، بما في ذلك احتجاز آلاف الأسرى، وانتهاك حرمة الأماكن المقدسة، وتهجير المواطنين الفلسطينيين خاصة في القدس الثريف، والاستمرار في ممارسة سياسة الفصل العنصري والتطهير العرقي ناهيك عن مواصلة سياسة الحصار الجائر لقطاع غزة. يحدث ذلك كله تحت أنظار المجتمع الدولي دون

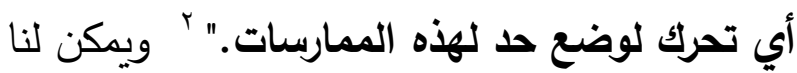
من خلال هذه البنية العاملية أن نتحدث عن عاملين: عامل (مرسِل)، وعامل (مرسل إليه). فالعامل الأول هي ذات الأمير سعود الفيصل وعله لهريل (مواقف المملكة العربية السعودية والأمة العربية الإسلامية، وقد تم التعبير عن ذلك بضمير "تحن" ذي الطبيعة الإدماجية في قوله: ولنا أن نتساءل هنا) أما عامل المرسل إليه فهم المجتمع الدولي بما لإنها

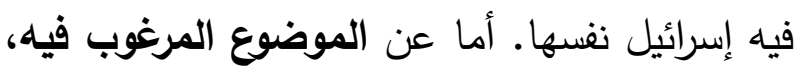
فهو إثبات أحقية الثعب الفلسطيني للعيش الكريم فوق أرضه. بيد أن ثمة مجموعة من العوامل
ولا يعني العامل - هنا- الشخصية فقط، بل هو مفهوم شامل، قد يعني المؤسسات والقيم والأفكار والفضاءات والأشياء وغيرها من المفاهيم المجردة، كالسعادة، والفرح والحق والخير... وتتسم البنية

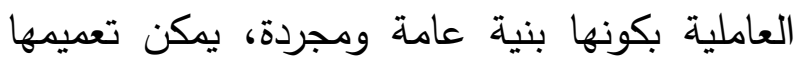
على الكثير من الظواهر والنصوص والخطابات، وترتبط هذه البنية العاملية بشكل وثيق ومتصل بالبرامج السردية التي تتبني عليها الخطابات. ومن هنا، فإن البرامج السردية هي وحدات سردية تنبثق عن تركيب عاملي قابل للتطبيق على كل أنواع الخطابات.' ويكثف التحليل السيميائي لخطابات الأمير سعود الفيصل عن وجود شبكة من الاختلافات والانزياحات، تبنى عليها الدلالة داخل خطاباته. وهي خطابات تتكئ على عناصر المعجم السياسي الدولي. يقول الأمير سعود الفيصل: "السيدال الرئيس.. تثكل السنة الحالية ؛ ا.بام علامة مهمة بالنسبة للقضية الفلسطينية كونها سنة التضامن مع الثعب الفلسطيني، ومن المؤلم أن يتزامن ذلك مع ما شهذناه هذا العام من عدوان إسرائيلي غاشم يرقى إلى جرائم حرب ارتكبتها إسرائيل في قطاع غزة في تجاهل إسرائيلي صارخ للإرادة الدولية وأحكام القانون الدولي. ولنا أن عيل نتساءل هنا: متى سوف يتحرك المجتمع الدولي لإنصاف الثعب الفلسطيني وردع إسرائيل عن ا - جوزيف كورتيس: مدظل إلى السبميائية السردية والخطلية، ترجمة الدكور جمل حضري، مطبعة الجسور بوجده، الطبعة

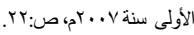


المعيقات (سياسة الاحتلال الإسرائيلية، بعض مواقف الفلسطيني في سعيها لامتلاك موضوعها كما يتجلى المجتمع الدولي) تقف في وجه العامل الذات الثعب ذلك واضحًا:
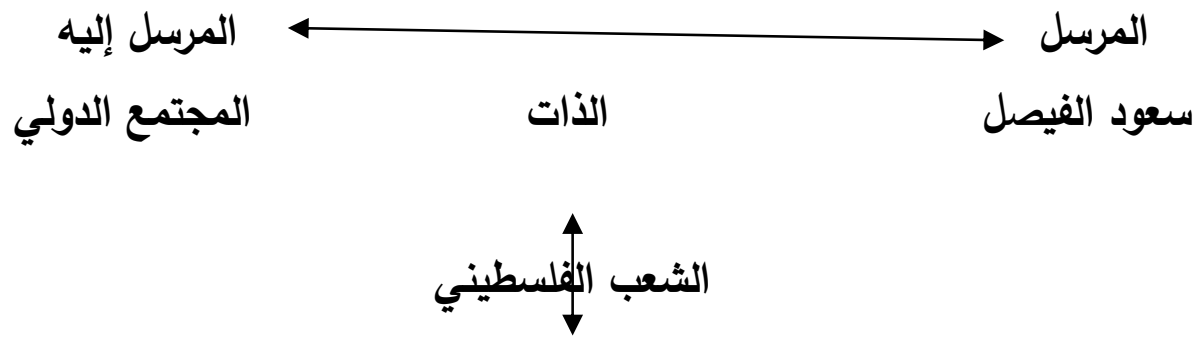

\section{الموضوع}

إثبات أحقية الشعب الفلسطيني للعيش فوق أرضه

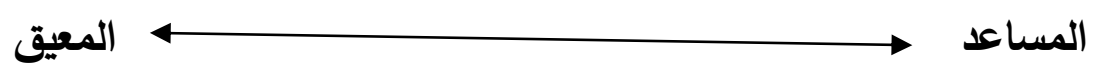

\section{سياسة إسرائيل العنصرية}

فالخطاب السياسي هنا يشيّيّ القيم المعرفية حول

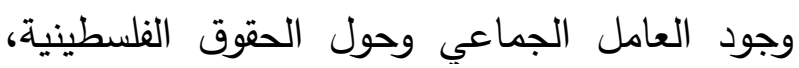

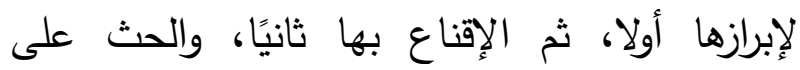

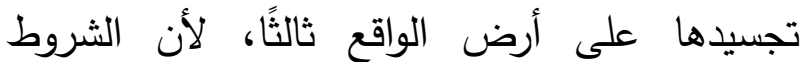

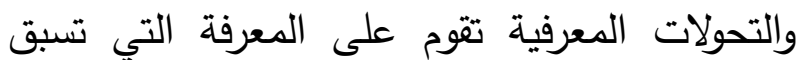

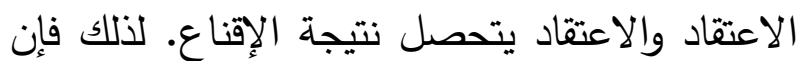

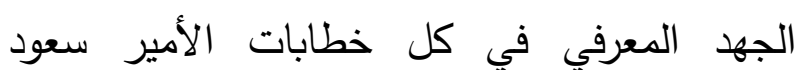
الفيصل يتخذ هذه الآلية في البناء:

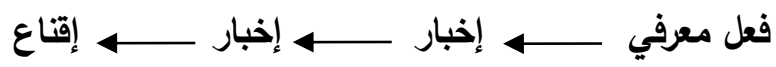

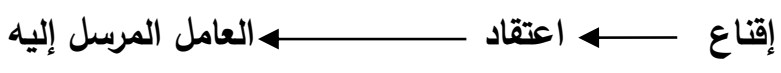
وجود الثعب الفلسطيني

ويعد الاعتقاد شرطًا أساسيًا لانخراط المجتمع الدولي لفيطي في إيجاد حل عادل للقضية ويرمي إلى تحقيقها، والاقتناع بها، وهي قضية تقوم على تتمية المعرفة حول: الوجود الإنساني للعامل الجماعي المتمثل في الثعب الفلسطيني-الحقوق الفلسطينية، الحق في الأرض، والحق في عدم تهويد القدس الثريف وتغيير تركيبته

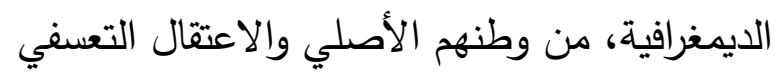

مواقف المملكة السياسية الثابتة

وبلغة السيميائيين فإن الفعل المعرفي في هذا لئهي الخطاب يرمي إلى "تنمية المعرفة والإدراك" عبر الفير عنصرين أساسيين هما: الوجود الإنساني والحقوق الإني الوطنية الفلسطينية عند الآخر • ونحن بصدد تحليل خطاب سياسي يستحضر، ولاشكّ، قطبية التواصل

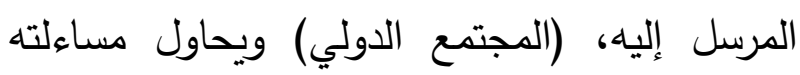

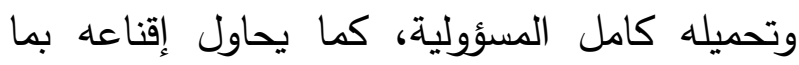
يقدمه من أدلة وحجج تسند العناصر الرئيسية في الخطاب. لذلك يستدعي الخطاب، اقتضاء مجموعة الخابة

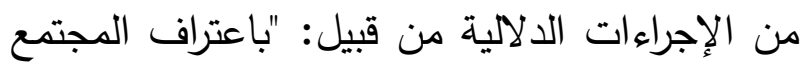

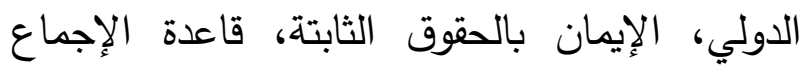

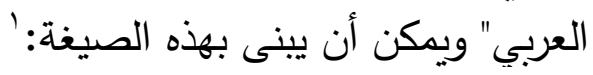

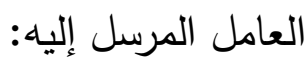

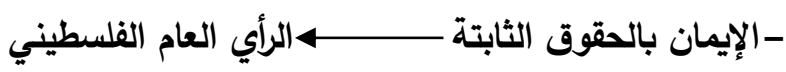

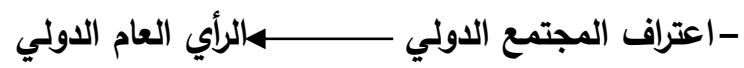

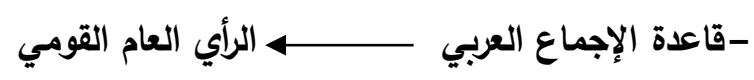

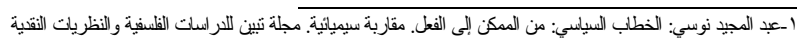

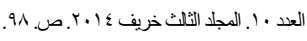


الفلسطينية) إلى الاتصال به بشكل مستمر.ّ و لقد أبرزت لنا هذه الخصائص اللسانية في بعدها

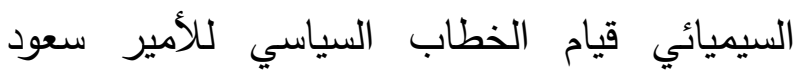
الفيصل على استراتيجية شرعية للفاعل السياسي وما ارتبط بها من تسويخ لهذه الشرعية، بالتركيز على الثى

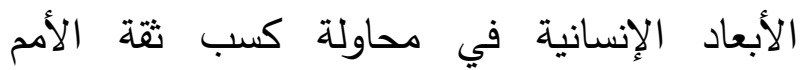

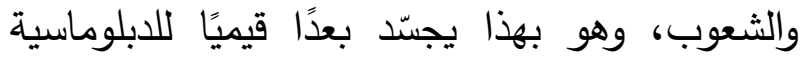
السياسية السعودية وحقيقة تاريخية أمام العالم بأسره. لهذا فإن المعنى داخل هذه الخطابات، من وجهة

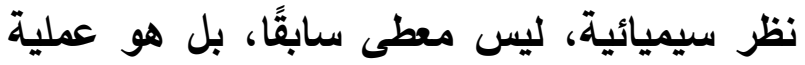
يثيد بها ذاته ضمن قيود تفرضها أنحاء الأنساق لئه الدالة على كل وحدة، والمقصود بالنحو مجموعة من القواعد الخاصة باشتغال كل نسق على حدة،

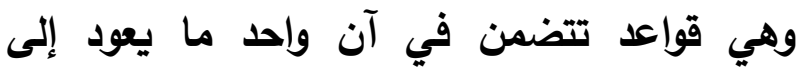

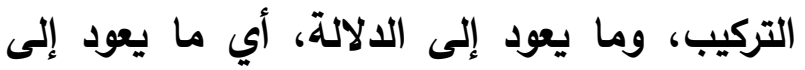

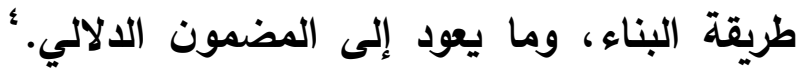

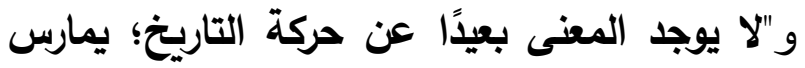

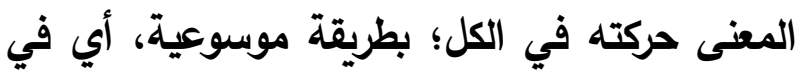
العلاقة مع عوالم اجتماعية ثقافية من المعرفة تديرها كل ذات حسب ما ترى، متكئة على اهتماماتها

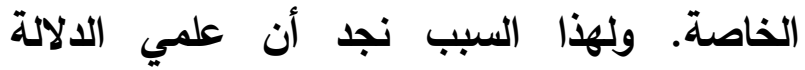
وإلتداولية كما أثار إيكو في نظرية التئل السيميائية متلازمان دائمًا. فلا يتم تحليد الوحدات الثقافية من

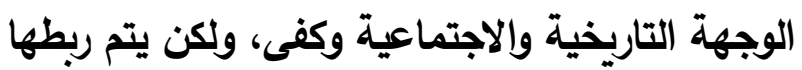

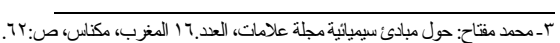

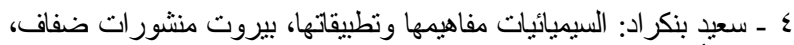

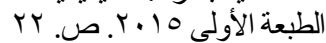

لأبنائه... كل هذا لإقناع المرسل إليه بهذه القيم ولجعله ينخرط في الاعتقاد بأهمية هذه القضايا المصيرية بالنسبة للشعب الفلسطيني. وإن الاعتقاد

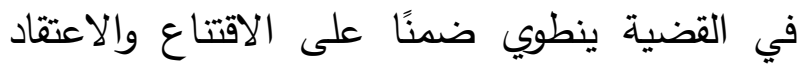
بعدم صواب الأطروحة المضادة التي يقوم بتثييدها العامل المعيق المتمثل في سياسات إسرائيل

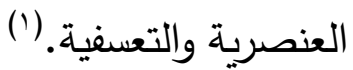

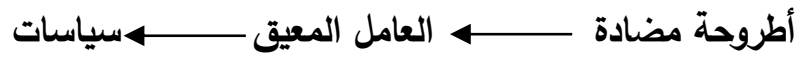

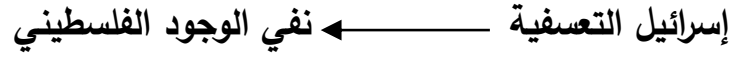
وعلى هذا المنوال، "يثكل هذا النموذج العاملي أساس تثكل الخطاب باعتباره يحتضن مجموعة من الأحداث...، أو هو بعبارة أخرى، شكل قانوني لتنظيم النشاط الإنساني، أو هو النشاط الإنساني مكثِفًا في بوتقة ثابتة، ويمكن أن نحدد هذا النموذج بصيغة بسيطة باعتباره شكلا يجمع داخله كل العوامل المحدة للفعل الإنساني: هدف للفعل، ما يدفع إلى الفعل، المستفيد من الفعل، الرغبة في الفعل، ما يقف في وجه هذا الفعل ويعوق تحقيقه أيضا."(r) إن هذه الإجراءات السيميائية في مستوياتها التركيبية

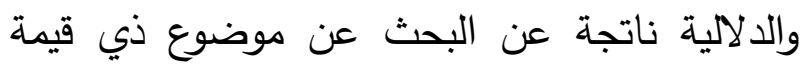
(وجود الثعب الفلسطيني وإثبات أحقيته التاريخية) يسعى المعني به (خطابات سعود الفيصل ومواقف المملكة السياسية والتاريخية الثابتة من القضية

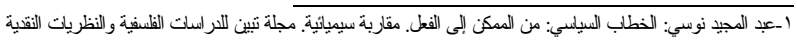

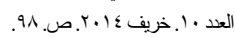

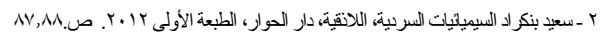


بتجربة المتكلم الداخلية الناقلة لأحاسيسه وهذا ما نستشفه في قول الأمير سعود الفيصل: "استميحكم

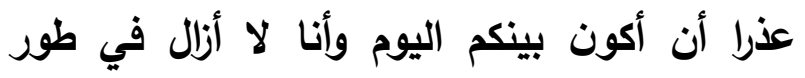
النقاهة إثر عملية جراحية كانت حالتي فيها أثبيه

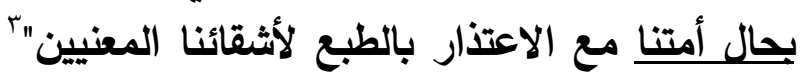

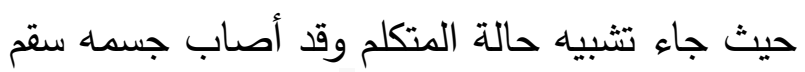

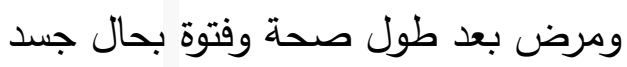

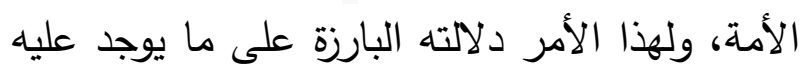

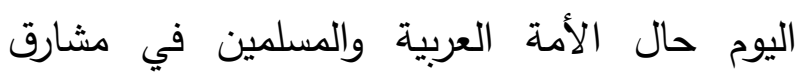

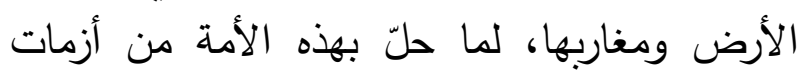

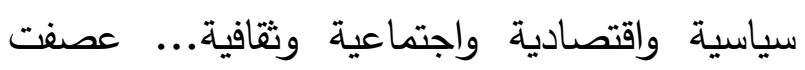

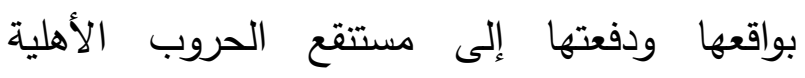
والصراعات الطائفية مما يتطلب علاجًا وتدخلا

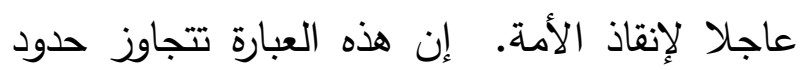
الذات المتكلمة إلى الآخر الذي تفصح الأنس عنده العبارة.

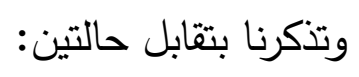

وتفعيلها ووضعها في خضم السياق وفي العمليات

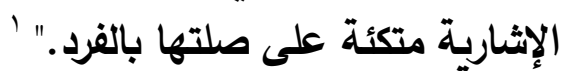
r r المماثلة والمجاورة السيميائية (التثبيه والكناية والاستعارة باعتبارها علامات سيميائية) يعدّ تحليل الاستعارة أداة مهمة لإبراز البعد الفكري

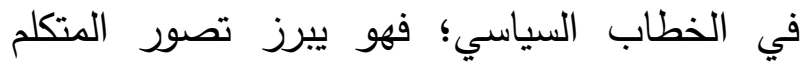
للمشاركين في الخطاب وللقضايا المناقشَّة. ونعتمد في هذا البحث مفهوم الاستعارة في السيميائيات

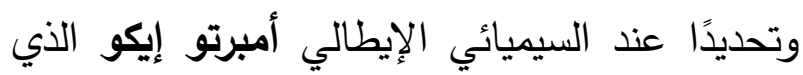
أثار إلى أنه "بقدر ما يكون الابتكار الاستعاري

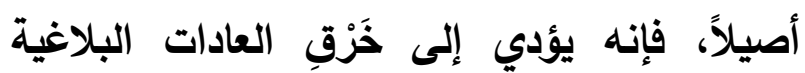
السابقة: "فمن العسير ابتكار استعارة جديدة استنادًا

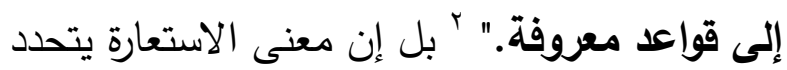

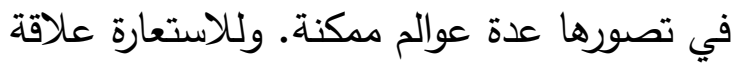

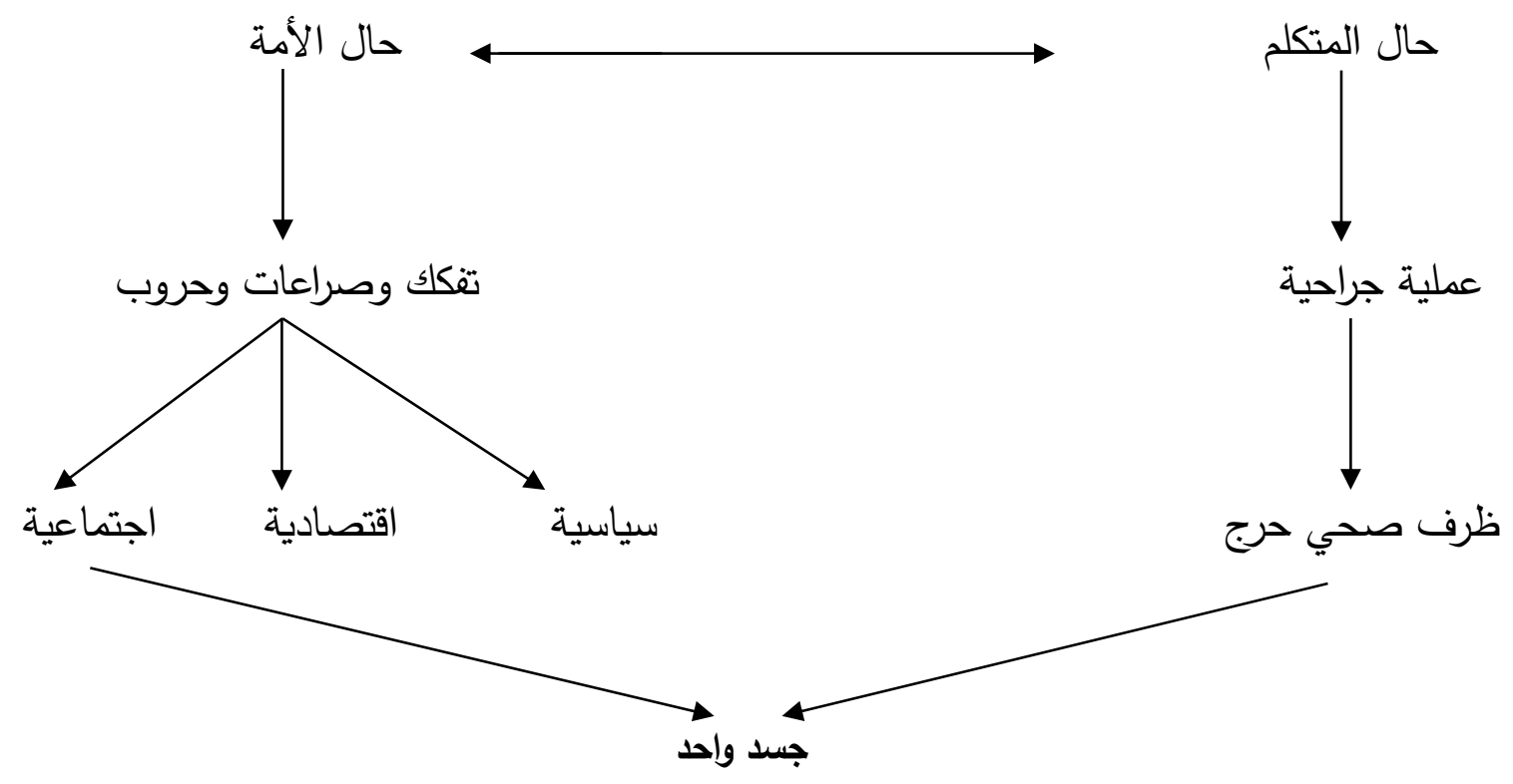

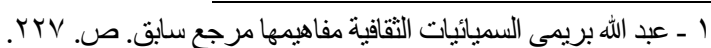

${ }^{3}$ - https://www.al-jazirah.com/2015/20150401/ln56.htm

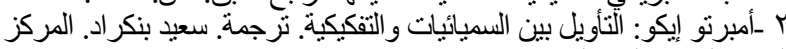

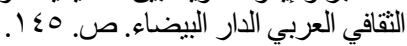


أنتج فيها الخطاب، وهذه المعرفة هي التي تساهم في الانتظام المؤدي إلى خلق الانسجام الداخلي للنص.

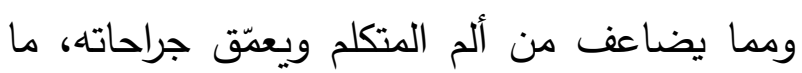
يحاك ضد اليمن السعيد وقد بدت علامات هذا لئات التوتّر في قوله: "إن اليمن السعيد.. يئن من النهات

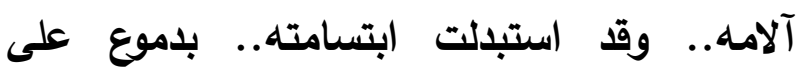
القتلى.. وألم على ضحاياه.. فتنة تكاد تقود اليمن

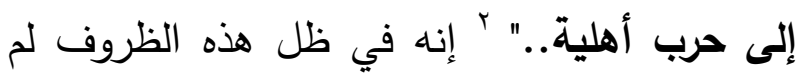
يعد اليمن هو ذالك اليمن السعيد المزدهر. ملايين

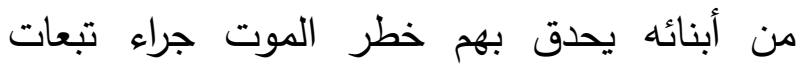
الحرب الأهلية، لكن وصف الأمير سعود الفيصل له بالسعيد تيمنًا بموقعه ومكانته وحضارته وتاريخه العيق والمتجذر وهو تاريخ عبثت به الأنظمة غير الشرعية والإيديولوجيات المتطرفة والمتآمرة التي تالتي جرفت اليمن إلى فتن عظيمة تنذر بمخاطر لا لحمد الإيدات

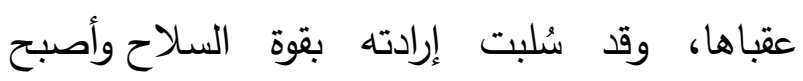
الإنسان اليمني رهينة غيره. وقد عبر عن هذا الأمير سعود الفيصل في قوله: "إن ميليشيات الحوثي.. وأعوان الرئيس السابق وبدعم إيران أبت إلا أن تعبث في اليمن.. وتُعيد خلط الأولق وتسلب الإرادة اليمنية بقوة السلاح.. وتنقلب على الثرعية الاستورية وترفض كل الحلول السلمية تحت قوة السلاح المذمومة.." " ولأن أمن اليمن جزء لا يتجزأ
إن وصفا من هذا النوع يستند إلى شفرات ثقافية

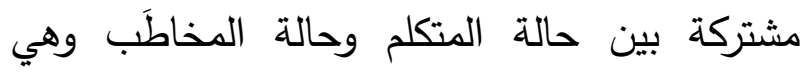
شفرات تثكلت وتطورت داخل العملية الإبلاغية. فالمتكلم واع جدًا بمصير الأمة انطلاقًا من تجربته الإلاثية

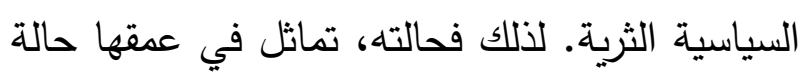
الأمة المشروخة وتذكرنا عبارة الأمير سعود الفيصل هذه باستعارة الجسد الواحد الذي يشعر بوحدة الأمة إذا اشتكي منه عضو تداعي لله سائر الجسد بالسهر والحمى. كما أنها حالة دالة على وجوده الذاتي، وهي دالة في الوقت نفسه على وجود الآخر

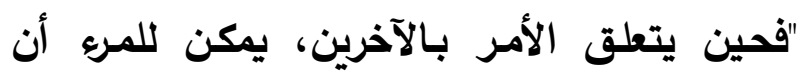
يعيش الصورة الخارجية بوصفها صورة مكتملة ونهائية، وكأن ما ينقص صورة الذات يوجد في الآخر واكتمال صورته المدركة، فالذات لا تعيش إلا

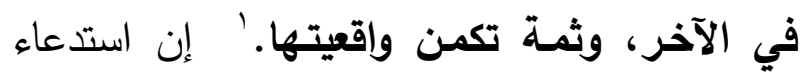

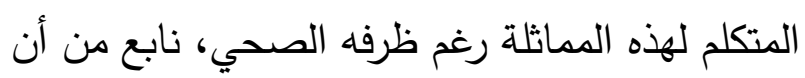

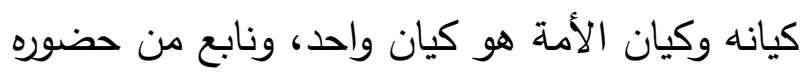
الدائم وغيرته وقوته في الدفاع عن قضايا العروبة بفكر ثاقب وقدرة على قراءة الواقع واستشراف

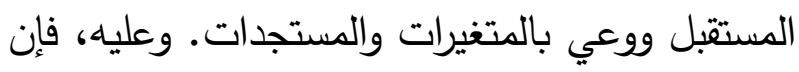
المعنى، بالاستاد إلى فرضية المماثلة القائمة على بلى بالئي التثبيه يُبنى وفق استراتيجية تتيمها الذات المتكلمة بناء على معرفتها الواعية بالسياقات التداولية التي 1 ـ ـ ـريد الزاهي ، النص والجسد والتأويل، أفريقيا الثرق. الطبعة الأولى 
العربي لا يعنيكم، وما تفعلونه عدوان وإرهاب لا بـ أن ينتهي. ولن يغير من هذه الحقيقة شيء مهما

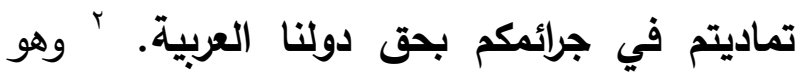
خطاب يرسم المعالم الواضحة للخطر الإيراني

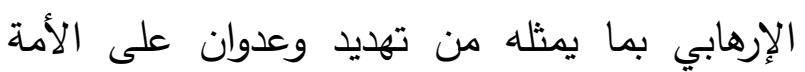
العربية. فلا وصاية لإيران على أي دولة عربية؛ فالعالم العربي لا يعنيكم وإذا تدخلتم فيه سمعتم ما لا لإيه يرضيكم، عملا بالحكمة المأثورة في أقوال العرب. وبنفس النغم يردّ الأمير سعود الفيصل على بلى الرئيس الروسي فلاديمير بوتين الذي قال في أحد خطاباته: "إن روسيا تقف إلى جانب الثعوب العربية من بن دون أي تدخل خارجي، ويجب تسوية الأزمات في سوريا وليبيا واليمن على أسس القانون الدولي".

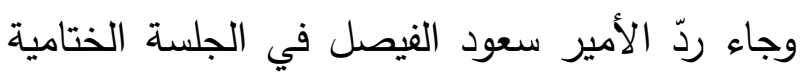
للقمة العربية، كاشفًا كل تتاقضات خطابها ردود، ومتهمًا إياه بدعم عدم الاستقرار في العالم العربي من خلال

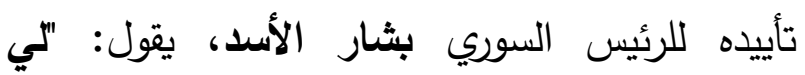

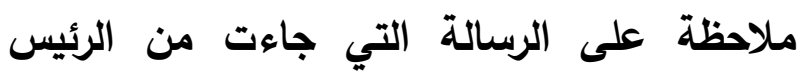

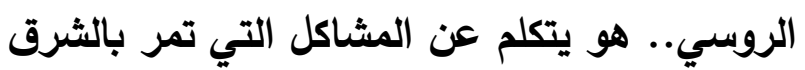

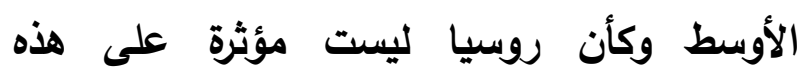
المشاكل. وعلى سبيل المثال سوريا. هم يتكلمون عن مآس تحدث في سوريا بينما هم جزء أساسي

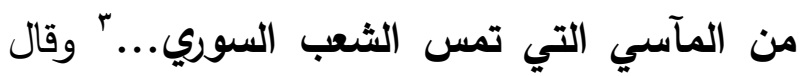
أيضا: "يمنحون من الأسلحة إلى النظام السوري ما

2. http://akhbar-alkhaleej.com/news/article/1091374

3 - https://www.youtube.com/watch?v=d97eReDitXw
من أمن المملكة والخليج والأمن القومي العربي، فلا

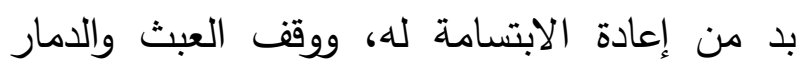

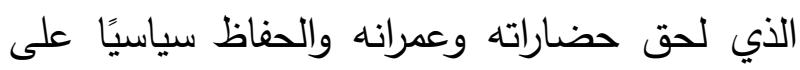
شرعيته ووحدته الوطنية وسلامته الإقليمية واستقلاله وسيادته. وهو ما جعل الأمير سعود الفيصل يقول:

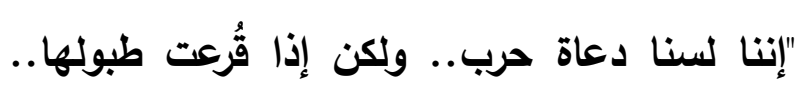

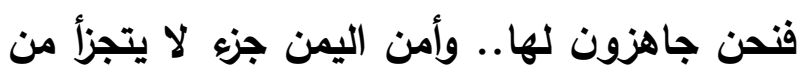

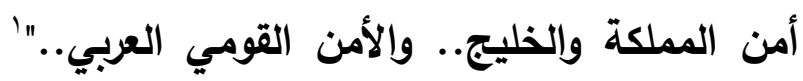

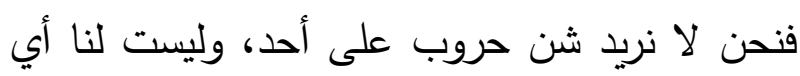
أطماع خارج حدودنا، ولكن لن نكون فريسة سهلة

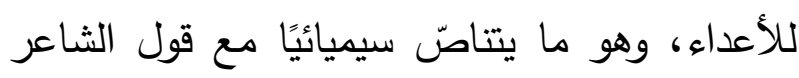
العربي الجاهلي عمرو بن كلثوم:

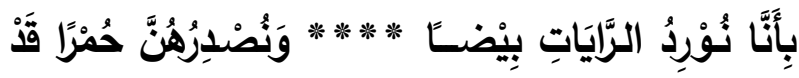
رُوِيْنَا إن الخطاب هنا، يحمل رؤية حاسمة وحازمة لا تقبل

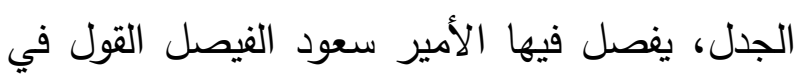
قضية تتعلق بمصير اليمن وهو مصير لا ينفصل

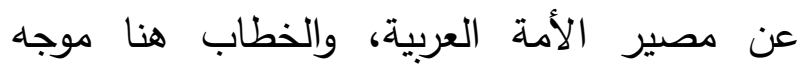
بالأساس ضد السياسات الإيرانية وإيديولوجيتها المبنية على سياسة تصدير الثورة وزعزعة الأمن والسلم والتدخل السافر في شؤون دول المنطقة.. وإثارة الفتن والثقاق بين أبناء العقيدة الواحدة. ممّا

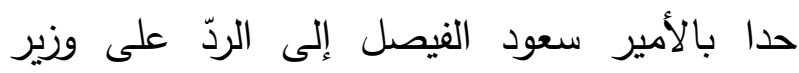
الخارجية الإيراني جواد ظريف بلإلاغة الإيجاز وبلاغة خير الكلام ما قلّ ودلّ في قوله: "إن العالم 
الأفكار والقيم التي تسمح بالتواصل وخلق حوار بين

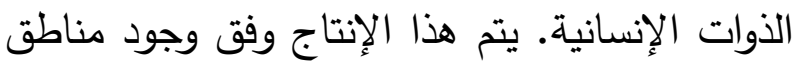

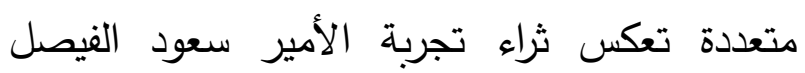
الإنسانية، وتتوع هذه المناطق هو الذي يفسر تعدد

$$
\text { التأويلات وغناها. }
$$

1- تحليل الممارسة الخطابية في خطاب الأمير

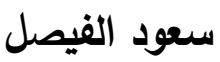

1-1 هوية الأمير سعود الفيصل السياسية في ضوء تمثيل الخطاب (الإنتاج والتلقي) إن العلاقة بين النص والأبنية الاجتماعية كما يقول فيركلف هي علاقة غير مباشرة تعتمد على وسائط معينة. وأول هذه الوسائط جميعًا الخطاب الذي عئي

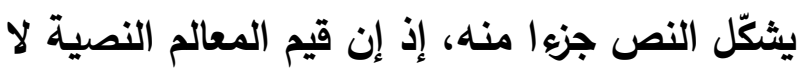
تصبح حقيقة واقعة، وفاعلة في المجتمع إلاّ إذا كانت مضمرة في التفاعل الاجتماعي حيث يجري إنتاج النصوص وتفسيرها في إطار من الافتراضات القائمة على المنطق السليم.` لذلك فمرحلة تحليل الممارسة الخطابية في مقاربة فِيرُكْلَتْ الجدلية العلائقية تهتم بدراسة إنتاج الخطاب واستهلاكه. ويمكن تقسيمها إلى مرحلتين فرعيتين هما: مرحلة إنتاج النص، وتُدَرَسُ فيها ظاهرتان خطابيتان هما: 'التناص' ونظام الخطاب"؛ حيثُ يشير التناص إلى فئى

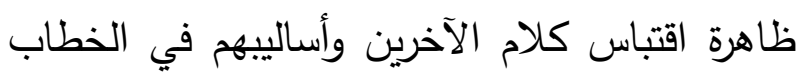

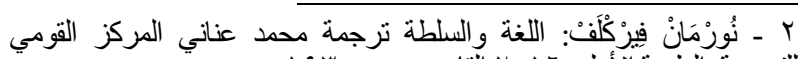

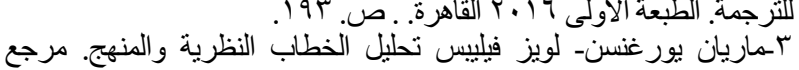

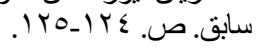

هو فوق حاجته لمحاربة شعبه." '. وقال: "روسيا تقترح حلولا سلمية وهي مستمرة في تسليح النظام السوري الذي يفتك بشعبه." وتعدّ كل هذه المظاهر الخطابية سواء في تجلياتها

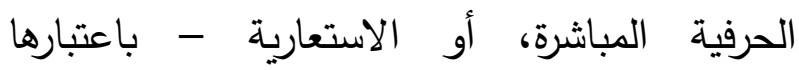
موضوعات سيميائية - عناصر مشكّلة للفضاء السيميائي الخطابي عند الأمير سعود الفيصل، سواء على مستوى التعبير أو المحتوى. إنها خطابات حبلى بالعلامات الذّالة على شرعية الممارسات

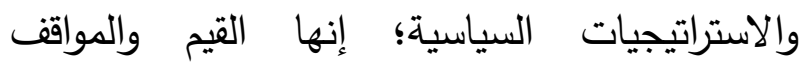
والأدوار الاجتماعية والسياسية والمبادئ الموجِهة داخل الخطاب التي تجلب الانسجام والاتساق لكل المستويات الأخرى داخل الفضاء السيميائي.في

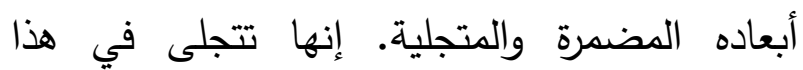
الفضاء انطلاقًا من مواقف وتعابير رمزية قادرة على ولى العهاده التأثير في أحاسيس المتلقي وعلى وضعيات تلفظه واختياراته القيمية. إنها في النهاية، أبنية سميائية متكاملة ومتسقة ومنسجمة تساعدنا في تحديد الهوية الخطابية والسياسية سواء الفردية أو الجماعية التي ينسبها الفاعلون السياسيون لأنفسهم داخل الفضاء السيميائي. بناء عليه، فإن فخطابات الأمير سعود الفيصل تؤكد حقيقة واحدة مفادها أن النشاط الإنساني في تعبيراته

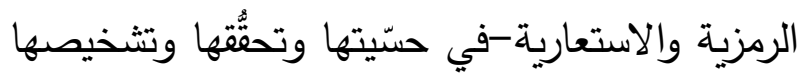
للأحداث والوقائع-قادر على إنتاج وتداول سلسلة 1 - https://www.youtube.com/watch?v=d97eReDitXw 
عند الأمير سعود الفيصل مجموعة الأنظمة الثقافية

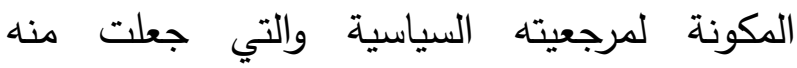
شخصية موسوعية تتفاعل مع كل الأحداث والمستجدات السياسية، مما جعل خطاباته نماذج قادرة على إعطاء تفسير للصراعات السياسية التي

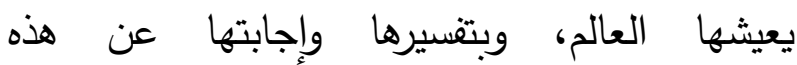
الصراعات تكون أيضا، قادرة على إعادة بنائه، وفق

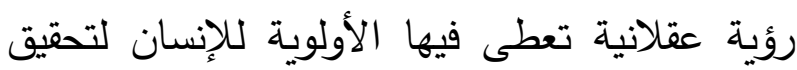
العدل والأمن والاستقرار ونشر السلام. ومن بين المرجعيات التي استدعاها الأمير سعود الفيصل ولنيل

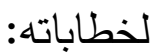
• الموسوعة الدينية: كثرة استشهاده بالقرآن الكريم وهي دعامة تحضر في خطاباته بشكل صريح كما في قوله: "أودعكم مستثهـا بقوله تعالى في القرآن الكريم في الآيتين من سوة النجم:( وأن ليس

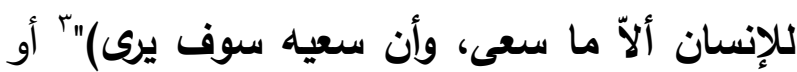
ضمني، كما في قوله: "إن أمتنا العربية التي حباها لهانها الله بالرسالة، فكانت خير أمة أخرجت للناس تأمر بالمعروف وتنهى عن المنكر"؛ حيث تتناص فكرة الخطاب هذه مع قول الله عزّ وجل: (كُنتُمْ خَيْرَ أُمَّةٍ

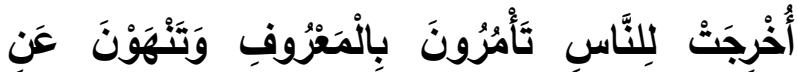

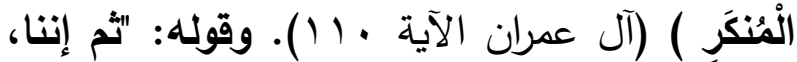
مع ذلك صبرنا وصابرنا، وانظلقت المملكة، في

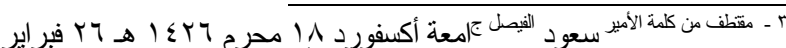

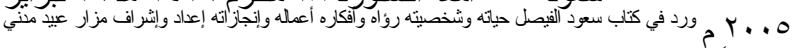

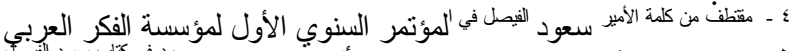

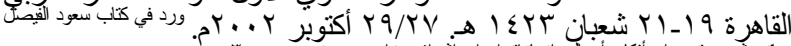

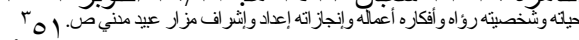

والاستشهاد بأفكارهم وآرائهم ولكل اقتباس آثار اجتماعية وثقافية وسياسية، وهو ما يدعو إلى الوقوف بالتتاص الموجود في النصوص ودراسة

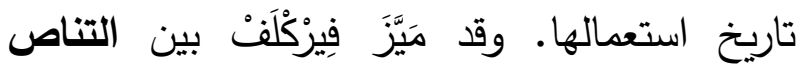
الظاهر' (الاعتماد الصريح على نصوص أخرى) والتناص المُكَِِِّّ (أي المتعلق بأنظمة الخطاب).

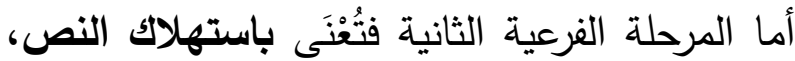

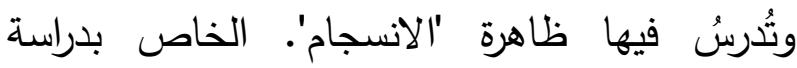
الأبعاد التأولية للسمات التتاصية لعينة الخطاب، أي تأثيرات هذه الظواهر الخطابية في الجمهور، ويدعو فِيْكْكَفْ في هذا السياق إلى دراسة استجابة الجمهور • وسنحلل استهلاك النص في مرحلة تحليل الممارسة الاجتماعية؛ بما أن هذه المرحلة تُعْنَى بدراسة الآثار الإقناعية والتأثيرية في المجتمع، والجمهور مكوِنٌّ من مكونات المجتمع. وينقسم تحليل الممارسة الخطابية بصفة عامة إلى قسمين: أ- تحليل التناص: ويسعى إلى تحديد طبيعة سلاسل التناص ووظائفها البنائية للهوية الخطابية للسياسي وكذلك سلطتها الإقناعية. " يجري تقاطع الخطابات عندما تتمفصل خطابات وأجناس مختلفة معًا في حدث تواصلي، فخلال تمفصلات جديدة للخطابات، تتغير الحدود داخل نظام الخطاب وبين أنظمة الخطاب المختلفة على حدّ سواء." ‘ ' حيث تثترك في الخطاب السياسي

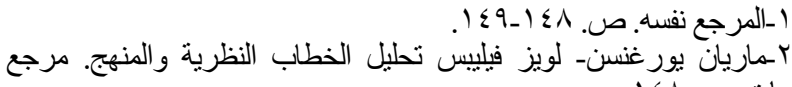
سابق. ص.1^) 
الفكرية العربية في لحظة تاريخية معينة وظلت أسيرة

أفكاره، حيث يقول: "وفي هذا الصدد يلاحظ محمد عابد الجابري أن النهضة العربية العديثة كانت

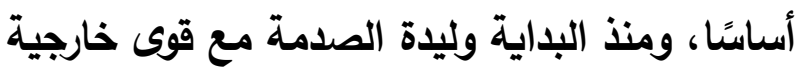

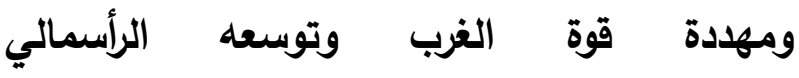

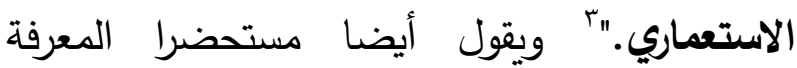

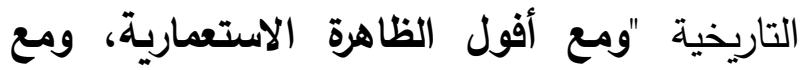
نهاية الحرب العالمية الثانية انتقل النظام الدولي إلى مرحلة جديدة قائمة على القطبية الثنائية." أ وإن حضور المعرفة التاريخية في خطابات الأمير سعود الفيصل، إنما هي لإنشاء علاقة متبادلة بين زمني الماضي والحاضر ، ولا يكون الماضي مصدرًا للاحتذاء والتقليد، بل للابتكار والتجديد والتعبير عن لن تجربة إنسانية يعاد فيها صياغة الماضي وفق رؤية حديثة تستجيب لمتطلبات العصر ومواجهة تحدياته. • الموسوعة العلمية الجغرافية والاقتصادية والبيئية: يقول الأمير سعود الفيصل: "لقد عوضت

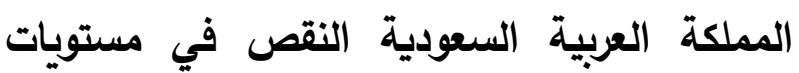
الإنتاج البترولي عن طريق الاحتفاظ بقدر إنتاج فائضة تصل ما بين 1,0 إلى r مليون برميل الاحسيل

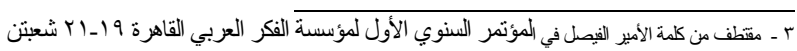

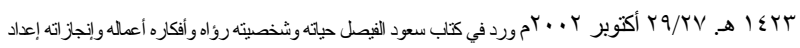

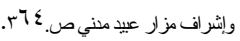

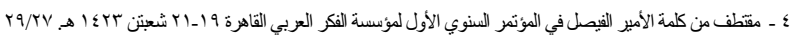

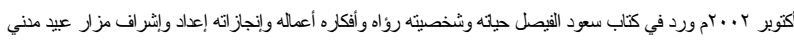

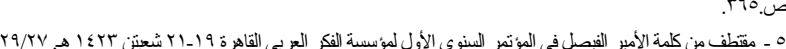

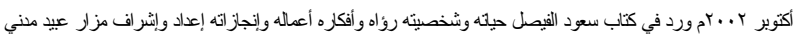

جنوحها العربي المثابر نحو السلم، تثارك الأسرة

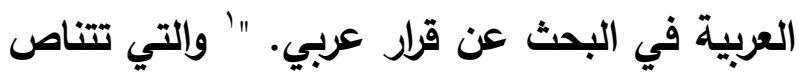

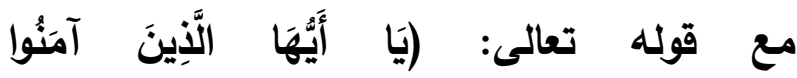

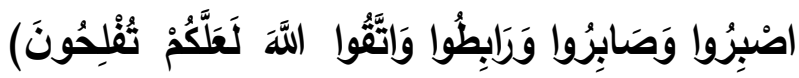

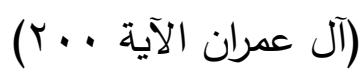
• الموسوعة الأدبية الثعرية: كثيرًا ما استخدم الابه الأمير سعود الفيصل ببراعة تامة تضمين خطاباته شينًا من الموروث الأدبي والثعري خاصدة، ليجعله لئه متتاسبًا والمعنى المراد تبليغه للمتلقي، بكل ما يحمله من ثقل التأثير والفاعلية، وصولا للفكرة المنشودة حيث يقول: وتسامت المملكة على الجراح وظلم ذوي القربى' التي تتناص مع دكمة الثاعر الجاهلي طرفة بن العبد وظلم ذوي القربي أثد مضاضة **** ** على المرو من وقع الحسام المهند • الموسوعة الفكرية والفلسفية والتاريخية: يستحضر الأمير سعود الفيصل في خطاباته أقوالا لمفكرين عرب أمثال محمد عابد الجابري وعبد الله العروي والعديد من التيارات الفكرية في انقسامها بين تيارت سلفية وأخرى توفيقية وثالثة موغلة في

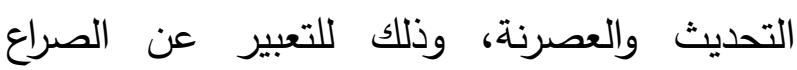
الفكري والإيديولوجي الذي سقطت فيه التيارات

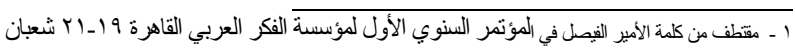

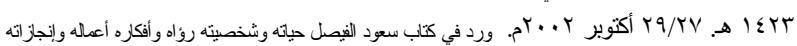

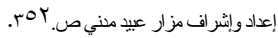

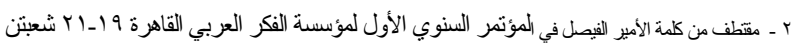

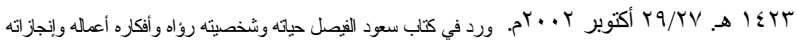

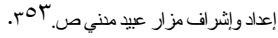


التصور، إلى بناء تصور ديناميكي للنص باعتباره

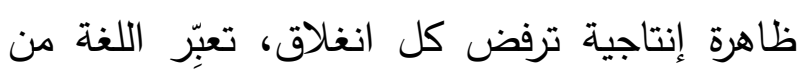
خلاله عن تفاعل بين الذات والآخر، وبينها وبين النص المقروء عبر حركة اختلافية تبرر هذا النسق

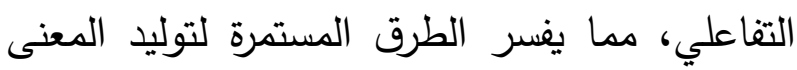

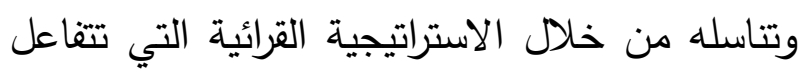
فيها معارف القارئ القبلية ومعارف النص الجديدة. وهو ما يفرض على القارئ تتويع مداخله القرائية.

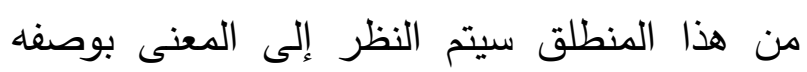
نتيجة اللقاء بين نصين النص المقروء ونص لنص

القارئ.

ب- تحليل أنظمة الخطاب: يسعى هذا التحليل

إلى إبراز الخصائص المميزة

والمشكلة لهوية الفاعل السياسي، وإظهار تجلياتها الخطابية وطبيعتها لدى الفاعل السياسي. وقد تم

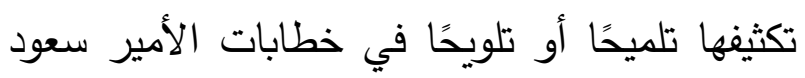
الفيصل ومن ثمّ النظر إليها باعتبارها ميثاقًا وتعاقدًا

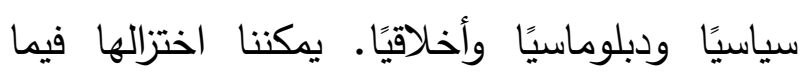
يلي:

- هوية دينية منسجمة مع مبادئ الثريعة الإسلامية في اعتدالها وسماحتها. - هوية عربية، في خدمة ونصرة القضايا العربية والإسلامية.

ب- عبد الله بريمي: مطارة العلامات مدظل إلى سيميائيات شارل سانترس بورس الإنتاج والتلقي دار كوز المعرفة للطباعة

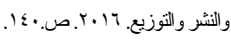

يظهر مما سبق، أن خطابات الأمير سعود الفيصل، وكما تتص على ذلك أدبيات اللسانيات

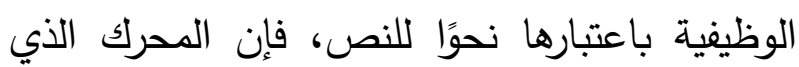

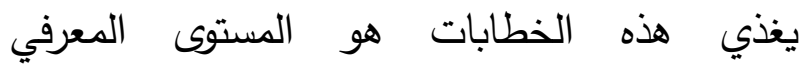

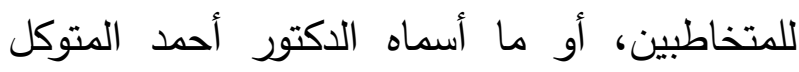

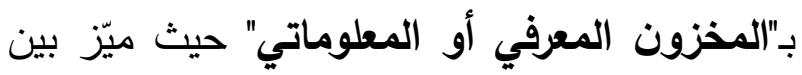

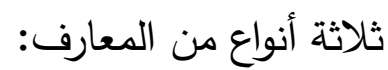
• • • المعارف العامة. فالأولى "تتعلق بمدركات المتخاطبين عن العالم"، والثانية مشتقة من عناصر المقام الذي تتم فيه عملية بلتئ التواصل"، والثالثة "يوفرها للمتخاطبين ما تم إيراده

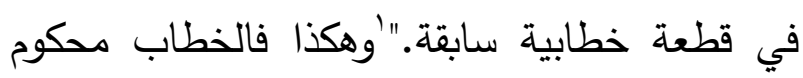
دائمًا بالمعرفة،" فلا خطاب بدون معرفة. ‘ والمعرفة

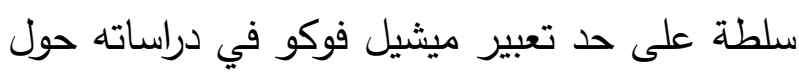
نظام الخطاب. إن الخطاب عند الأمير سعود الفيصل يشكل "لوحة فسيفسائية" من الاقتباسات المتكاثرة المتآلفة والمتباينة في الوقت نفسه، حيث تتفجّر من داخل النص النصات

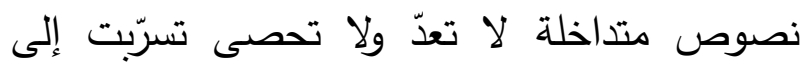
داخل النص بوعي من المؤلف أو دون وعي. وهكذا فالنص ليس مغلقًا ولا محصّنًا ضد التحخلات الهائلة التي تأتيه من كل حدب وصوب. يقودنا هذا

1 ـ أحد المتوكل: قضايا اللغة العربية في اللسنيات الوظيفية. بنية الخطاب من الجملة إلى النصن. الناشر: دار الأمان، الربطا.

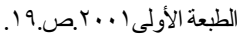

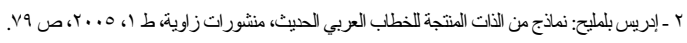


1- محدد الخطاب السياسي عند الأمير سعود الفيصل، هو كونه فعلا سياسيًا ووعاءً للعملية السياسية، وما يستتبع ذلك من ضرورة كون فئنْتِجِهِ

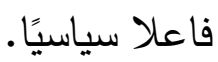

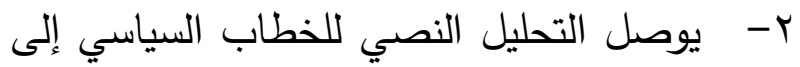
فهم أفضل لكيفية الاشتغال اللساني للعمليات الخطابية، ولكي تكون هذه المقاربة أنجع فإنها تسلّط الضوه على العلاقات والروابط بين الخطابات والممارسات والأبنية الاجتماعية والثقافية. r- عكست المستويات اللغوية والنصية والحجاجية

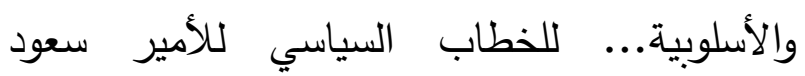
الفيصل التصورات الفكرية المكونة لهويته السياسية. ع - أدى الخطاب السياسي للأمير سعود الفيصل في بعده اللغوي الثكلي دورًا كبيرًا في عملية جذب لبريز

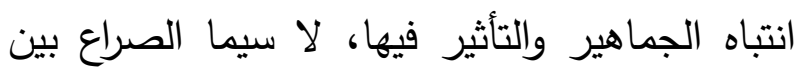
قوى الخير وقوى الثر والتتاص الديني والاستعارات الإبداعية.

0- مصداقية وشرعية الخطاب السياسي عند الإبهان الأمير سعود الفيصل، نابعة من توظيفه لخصائص

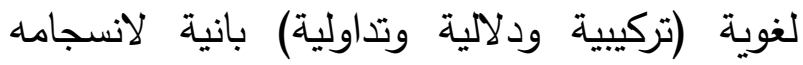
واتساقه (نحو النص). 7- ما يميز الخطاب السياسي عند الأمير سعود الفيصل هو مفهوم التداول؛ فالخطاب السياسي يكون فيه التداول ذا أولوية أساسية، وهو ما يدلُّ على أنه لنه

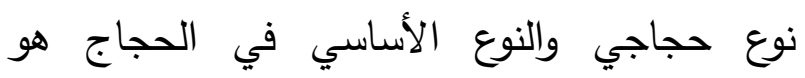
الاستد لال العَمَلِيُّ.
- هوية إنسانية أممية تتجلى في خدمة الأمن والسلم الدوليين، مع الالتزام بقواعد القانون الدولي هي وإلمعاهدات والمواثيق الدولية واحترامها. - هوية وطنية تتفانى في خدمة مصالح الوطن وحمايته والحفاظ على سلامة أراضيه واستقراره ونمائه، ورعاية مصالح المواطنين، وإعلاء شأن المملكة ومكانتها في العالم. - هوية عصرية،، تحاكي دبلوماسيًا (الدبلوماسية الثاملة) لغة العصر، وتتعامل مع أساليبه في مواجهة الأعباء وما يثهده العالم من تحولات. إن امتلاك الأمير سعود الفيصل لآليات الخطاب

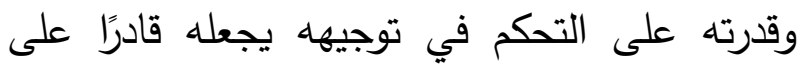
إنتاج سلسلة لامتتاهية من المعاني. والخطاب عنده له منطقه الداخلي لكنه في العمق منطق مؤسساتي. بمعنى آخر ، "إن الخطاب ليس ناتجاً بالضرورة من فن مؤن ذات فردية يعبر عنها أو يحمل معناها أو يميل

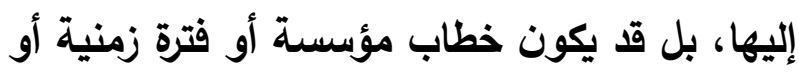
فرع معرفي ما."' فالخطاب معرفة والمعرفة سلطة، والسلطة هنا ليست في نزوعها التحكمي، بل في طرق تدبير وتصريف أفعالها بحكمة عالية وبرويّة ونجاعة تراعي المصلحة للعليا للوطن ومصالح المواطنين وشعوب الأمة العربية والإسلامية، وكل الأمم الداعية إلى الأمن والسلام والحوار والاعتدال ونبذ العنصرية والتطرف. استنتاجات: 
rا- ساهمت الخطابات السياسية، بمواقفها الدبلوماسية المشرّفة والمشرقة، للأمير سعود الفيصل في صناعة تاريخ مجيد لوطنه وأمته.

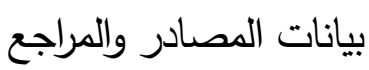
خطابات الأمير سعود الفيصل الواردة في كتاب: 1- سعود الفيصل حياته وشخصيته.. رؤاه وأفكاره.. أعماله وإنجازاته إعداد وإشراف نزار عبيد مدني. الطبعة الثانية الرياض. مركز الملك فيصل للبحوث والدراسات الإسلامية 9ب؟ الهـ r- كلمة الأمير سعود الفيصل في الدورة العادية الـ(79) للجمعية العامة للأكم المتحدة في نيويورك. المراجع العربية وإلمترجمة: 1- إيكو أمبرتو: التأويل بين السميائيات والتفكيكية. ترجمة. سعيد بنكراد. المركز الثقافي العربي الدار لئي البيضاء.

r- بريمي عبد الله: السميائيات الثقافية مفاهيمها وآليات اشتغالها مدخل إلى نظرية يوري لوتمان السميائية دار

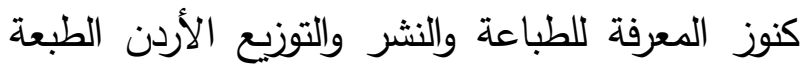

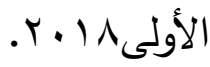
ץ- بريمي عبد الله: مطاردة العلامات مدخل إلى بلى سيميائيات شارل ساندرس بورس الإنتاج والتلتي دار كنوز المعرفة للطباعة والنشر والتوزيع. 17 • r. ع- بلمليح إدريس: نماذج من الذات المنتجة للخطاب

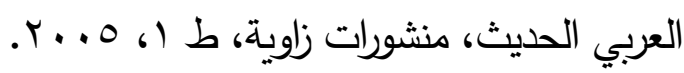
0- بنكراد سعيد: السيميائيات السردية، اللانقية، دار

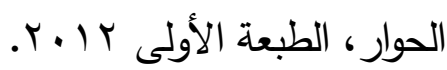

- الدراسات السيميائية والنقدية للخطاب مشروع - بحث متعدد المشارب والمنهجيات، يهتمُّ بدراسة القضايا الخطابية، ومساءلة الأنساق (الاجتماعية والسياسية والثقافية)، بالتركيز على دور اللغة في إنتاجها أو إعادة إنتاجها أو في مقاومتها واقتراح

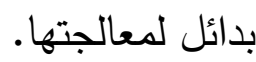

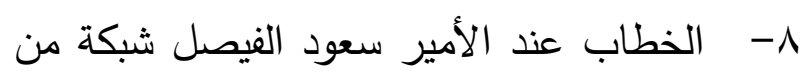
الممارسات السيميائية المنتجة في سياق معين وفي حقل من حقول الفعل السياسي والاجتماعي وأنَّهُ مازجّ لأصوات ونصوص ومواقع مختلفة. 9- يعمك الخطاب السياسي بشكل إناري:

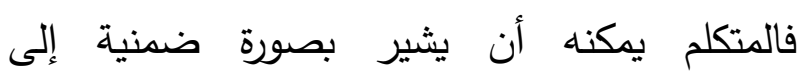

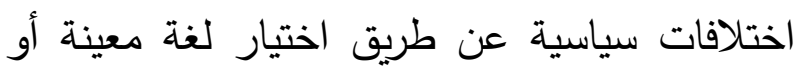
سمة من سماتها، ويكون ذلك باختيار الحديث بلغة دون أخرى أو بمصطلحات سياسية دون أخرى. وهذا يبرهن على أن الحدود بين المجموعات يمكن أن أن يعبَّرَ عنها بطريقة إثارية.

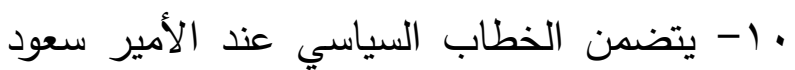
الفيصل تفكيرًا استعاريًا يُعبّرِ بواسطته عن كل ما يتعلَّقُ بالسياسات. 11- للخطاب السياسي تداعيات خاصة بالمراكز الشعورية للذهن. rا- يمزج الأمير سعود الفيصل في خطابه السياسي بين معارف موسوعية (دينية، علمية، أدبية، تاريخية، ثقافية...) جعلت من خطاباته ظاهرة تفاعلية وإنتاجية. 
با ا-فيركلف نورمان: اللغة والسلطة ترجمة محمد عناني

المركز القومي للترجمة. الطبعة الأولى 7 ـ ـ القاهرة. ع ا- الزاهي فريد: النص والجسد والتأويل، أفريقيا

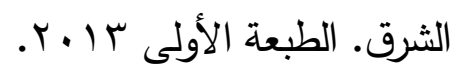

10- المتوكل أحمد: اللسانيات الوظيفية مدخل نظري

$$
\text { منشورات عكاظ } 1919
$$

71- المتوكل أحمد: قضايا اللغة العربية في اللسانيات الوظيفية. بنية الخطاب من الجملة إلى النصّ. الناشر :

$$
\text { دار الأمان، الرباط. الطبعة الأولى I . . Y. }
$$

IV مفتاح محمد: حول مبادئ سيميائية مجلة علامات، العدد.7 1 المغرب، مكناس.

11- نوسي عبدالمجيد: الخطاب السياسي: من الممكن إلى الفعل. مقاربة سيميائية. مجلة تبين للدراسات الفلسفية والنظريات النقدية العدد ـ ا. المجلد الثالث

$$
\text { خريف ع ا . ا. }
$$

9 19 نوسي عبد المجيد: الخطاب السياسي: من الممكن إلى الفعل. مقاربة سيميائية. مجلة تبين للدراسات

الفلسفية والنظريات النقدية العدد . . خريف ع ا ـ r. • r- يورغنسن ماريان - فيليب لويز : تحليل الخطاب النظرية والمنهج. ترجمة شوقي بوعناني مراجعة محمد المومني الطبعة الأولى المنامة البحرين 9 1 ـ ب.

\section{المراجع الأجنبية:}

1- Chilton, Paul (2004). Analyzing Political Discourse: Theory and Practice. London and New York: Routledge

2- Roger, Fowler \& Kress Gunther (1979). Critical Linguistics. In Roger Fowler, Bob Hodge, Gunther Kress \& Tony Trew. (1979). Language and Control. London: Routledge.
7- بنكراد سعيد: السيميائيات مفاهيمها وتطبيقاتها، بيروت منشورات ضفاف، الطبعة الأولى 0 ـ ب. . خطابي محمد: لسانيات النص مدخل إلى انسجام -V الخطاب الطبعة الأولى (999 المركز الثقافي العربي الدار البيضاء. 1- دايك فان: النص والسياق، استقصاء البحث في الخطاب الدلالي والتداولي، تصنيف الأفعال الإنجازية ترجمة: عبد القار قنيني إفريقيا الثرق الدار البيضاء

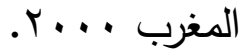

9- سعود المطيري مطلق: استراتيجيات الإقناع السياسي قراءة تحليلية لخطاب سمو الأمير سعود الفيصل للاكتور • الطبعة الثانية ؟ ا ـ ب. دار مملكة نجد للنشر والتوزيع. الرياض. • 1-عبد الرحمن طه: التواصل والحجاج، جامعة ابن زهر ، كلية الآداب والعلوم الإنسانية، أكادير • ؟9 9 (1، ا ا-فوكو ميشيل: نظام الخطاب. ترجمة محمد سبيلا دار التتوير • بيروت الطبعة الأولى ع^ه1 ـ . rا-كورتيس جوزيف: مدخل إلى السيميائية السردية والخطابية، ترجمة الدكتور جمال حضري، مطبعة الجسور بوجده، الطبعة الأولى سنة V +. . م.

3- Ruth, Wodak (2009a). The Discourse of Politics in Action: Politics as Usual. Basingstoke, UK: Palgrave Macmillan.

4- Teun, Van Dijk (1997). what is Political Discourse Analysis? In Jean Blommaert \& Chris Bulicaen (Eds.), Political Linguistics. Amsterdam: Benjamin. 


$$
\text { مواقع على الإنترنت }
$$

1- https://www.orientnews.net/ar/news_show/88858

2- https://fhras.net/47217/
3- https://www.al-

jazirah.com/2015/20150401/ln56.htm

4- http://akhbaralkhaleej.com/news/article/1091374

5- https://www.youtube.com/watch?v=d97eRe DitXw 


\title{
Semantics of Saudi Political Discourse: A Significations Study of Prince Saud Al-Faicel Speeches
}

\author{
ALSOLAMI , ABDULLATEEF MARZOUQ \\ Associate Professor of Linguistics, University of \\ Jeddah - Kingdom of Saudi Arabia
}

\begin{abstract}
. the present study p urports to shed light on the problematics of the relationship between language and politics in general and on the semiotic formulation, in particular, of Prince Saud Al-Faicel political discourse. It attempts to explain how this discourse succeeded to formulate a political model capable, thanks to its argumentative and rhetorical tools, to decode or unlock regional crises and international transformations in order to make historical decisions. Such problematics reflect our particular perception of political discourse in its relationship with textual linguistics, along with the powerful semiotic discursive strategies and practices ever present in the analysis and interpretation of the political discourse of Prince Saud Al-Faicel. The Present study relied on an analytic frame following Norman Fairclough's model and other semiotic studies structured around lexicon and language construction. It also paid attention to analyzing the intricacies characterizing relations and strategies within power relations. The originality of the present study can be seen in its combination of the textual approach with the analytical one when dealing with political discourse.
\end{abstract}

Keywords: Language, politics, Discourse, Semiotics, Saud Al-Faicel, Critical Discourse Analysis 